\title{
Twenty years of ambient observations of nitrogen oxides and specified hydrocarbons in air masses dominated by traffic emissions in Germany
}

\author{
Christian Ehlers, Dieter Klemp, Franz Rohrer, ${ }^{*}$ Djuro Mihelcic, \\ Robert Wegener, Astrid Kiendler-Scharr and Andreas Wahner
}

Received 18th November 2015, Accepted 9th December 2015

DOI: $10.1039 / c 5 f d 00180 c$

The analysis of the individual composition of hydrocarbon (VOC) mixtures enables us to transform observed $\mathrm{VOC}$-concentrations into their respective total VOC-reactivity versus $\mathrm{OH}$ radicals $\left(R_{\mathrm{VOC}}=\Sigma\left(\mathrm{KOH}_{\mathrm{OVOC}} \times\left[\mathrm{VOC}_{i}\right]\right)\right)$. This is particularly useful because local ozone production essentially depends on this single parameter rather than on the details of the underlying hydrocarbon mixture (Klemp et al., Schriften des Forschungszentrums Jülich, Energy \& Environment, 2012, 21). The VOC composition also enables us to pin down the major emission source of hydrocarbons in urban areas to be petrol cars with temporarily reduced catalyst efficiency (the so-called cold-start situation) whereas the source of nitrogen oxides $\left(\mathrm{NO}_{x}=\mathrm{NO}+\mathrm{NO}_{2}\right)$ is expected to be nowadays dominated by diesel cars. The observations in the vicinity of main roads in German cities show a decrease in the ratio of $\mathrm{OH}$ reactivities of $\mathrm{VOC}$ and $\mathrm{NO}_{2}$ $\left(R_{\mathrm{VOC}} / R_{\mathrm{NO}_{2}}\right)$ by a factor of 7.5 over the time period 1994-2014. This is larger than the expected decrease of a factor of 2.9 taking estimated trends of $\mathrm{VOC}$ and $\mathrm{NO}_{x}$ traffic emissions in Germany (Umweltbundesamt Deutschland, National Trend Tables for the German Atmospheric Emission Reporting, 2015), during this time period. The observed reduction in the $R_{\mathrm{VOC}} / R_{\mathrm{NO}_{2}}$ ratio leads to a drastic decrease in local ozone production driven by the reduction in hydrocarbons. The analysis reveals that the overall reduction of ozone production benefits from the low decrease of $\mathrm{NO}_{x}$ emissions from road traffic which is a consequence of the eventual absence of catalytic converters for nitrogen oxide removal in diesel cars up to now.

\section{Introduction}

Over the last 20 years (1994-2014), the compliance with ozone regulations of the European Union (EU) for the protection of human health has slowly improved in Germany. On the other hand, the average surface ozone concentration measured at the German Global Atmosphere Watch (GAW) station in Hohenpeissenberg has 
remained almost constant over the last 25 years (Fig. 1). To put this into a proper perspective, these observations in Germany can be compared to ozone data from the GAW station at the western coast of Europe in Mace Head, Ireland. Ozone is photochemically produced in the troposphere by the degradation of VOC in the presence of nitrogen oxides, ${ }^{1}$ primarily over continents. In the troposphere, ozone is relatively long lived and has a life-time of about one month. As a consequence, its near-surface concentration shows only little variability over large areas. The predominantly westerly winds transport so-called background ozone from America to Europe's West Coast (see ref. 2). Observations at Mace Head give a very good picture of these ozone background concentrations which are then altered by photochemical production and surface deposition during the further transport of air parcels over France and Germany towards the East. At Hohenpeissenberg, the observed annually averaged surface ozone concentrations are larger then those at Mace Head during the 1990s, similar from 1999 to 2006, and smaller after 2007. The magnitude of this decrease at Hohenpeissenberg relative to Mace Head is on the order of $10-15 \%$ over 25 years. In fact, this decrease has not only been caused by changes in Germany since air parcels on their way from the Atlantic also pass France and other European countries. But nevertheless these observations show a general trend towards smaller ozone production in Western Europe.

The annually averaged concentrations themselves at Hohenpeissenberg are far lower than the target value for the protection of human health defined in the EU ozone regulations of $120 \mu \mathrm{g} \mathrm{m} \mathrm{m}^{-3}$ (for averaged episodes of 8 hours). A better insight into ozone reduction achievements in Germany is possible by looking at episodes of large ozone concentrations, popularly called ozone-alerts (see also Section 4.3). And here the improvements are obvious. Especially, the violations of the EU ozone alarm threshold $\left(240 \mu \mathrm{g} \mathrm{m}^{-3}\right)$ vanished completely ${ }^{4}$ (Fig. 2). These effects are likely to be caused largely by trends of pollutants emitted by road traffic in city districts. Here we show ambient observations of nitrogen oxides $\left(\mathrm{NO}_{x}\right)$ and hydrocarbons (VOC) in urban environments spanning this time period. To understand the observed trends of the ratio of $\mathrm{VOC} / \mathrm{NO}_{x}$ in inner city districts, we

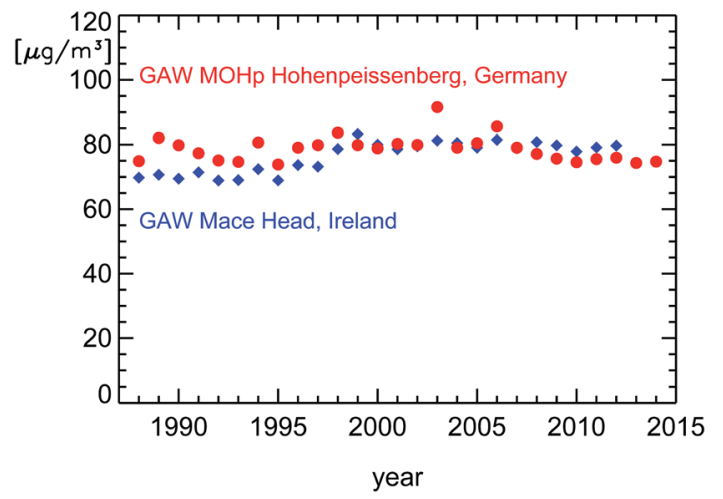

Fig. 1 Averaged annual surface ozone concentrations observed at the GAW stations Mace Head, ${ }^{2}$ Ireland (blue diamonds), and Hohenpeissenberg, Germany (red circles). The data from Hohenpeissenberg for the time period until 2010 are taken from the literature. ${ }^{3}$ The later data were kindly supplied by the German Meteorological Service (DWD) and are preliminary. 


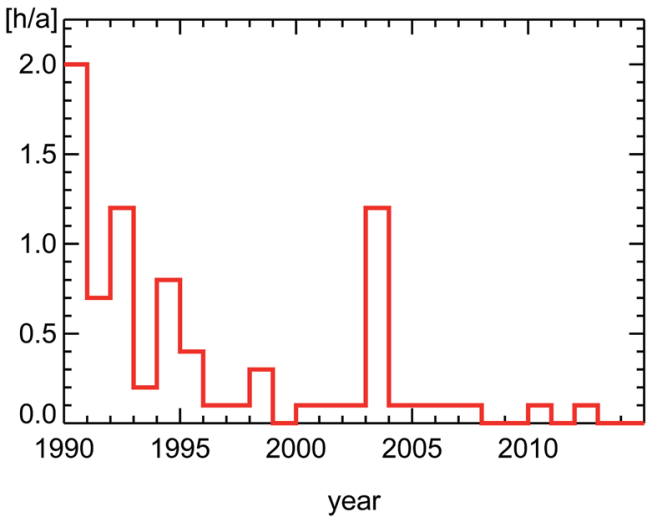

Fig. 2 Average number of hours per year for all survey stations in Germany exceeding the European ozone alarm value $\left(240 \mu \mathrm{g} \mathrm{m}^{-3}\right.$, see ref. 4).

will first discuss the basic features of diesel and petrol motors, the effect of catalytic converters, and the trend of cars and fuel use in Germany.

\subsection{Basic features of diesel and petrol engines}

The major difference between diesel and petrol engines is the concentration of oxygen inside the cylinders when the fuel vapor is ignited. That depends on the fuel-to-air ratio $\lambda$ which is determined by the engine management, nowadays handled by an on-board computer. If the amount of oxygen matches the requirement of stoichiometrical combustion, all of the fuel is burned and no oxygen is left over. This is the case in the engine of a petrol car. That specific fuelto-oxygen ratio is called $\lambda=1$. Its compliance is monitored at all times by a $\lambda$-sonde and adjusted by the on-board computer within very small limits. Diesel engines use a very large excess of oxygen at approximately $\lambda=3$ which does not permit verification by a $\lambda$-sensor. Such an oxygen excess has important consequences for the emissions of pollutants by the car. Due to the larger amount of air mixed with the fuel, the temperature inside the cylinder of a diesel car is lower than that of a petrol car. That is responsible for the smaller $\mathrm{NO}_{x}$ emissions of a diesel compared to a petrol engine ${ }^{5}$ because higher temperatures favor the production of nitrogen oxides. ${ }^{5}$ In both types of engines $\mathrm{NO}_{x}$ is almost exclusively emitted in the form of NO. A higher amount of oxygen favors the oxidation of VOC so that their emission is also much smaller in diesel than in petrol cars. Fig. 3 illustrates these basic features of the two engine concepts. As a consequence, in the absence of catalytic converters, diesel cars emit much less VOC and $\mathrm{NO}_{x}$ than petrol cars. That was the case until 1985 (introduction of the G-Kat in Germany) when subsequently for both kinds of car catalytic converters were introduced to meet the requirements of a more stringent environmental policy.

\subsection{Catalytic converters for diesel and petrol engines}

For petrol cars, the so called 3-way-catalyst or G-Kat oxidizes CO and VOC with oxygen to $\mathrm{CO}_{2}$ and reduces $\mathrm{NO}$ with $\mathrm{CO}$ to $\mathrm{N}_{2}$ and $\mathrm{CO}_{2}$. Since oxidation and reduction processes are taking place at the same time, this kind of catalytic 


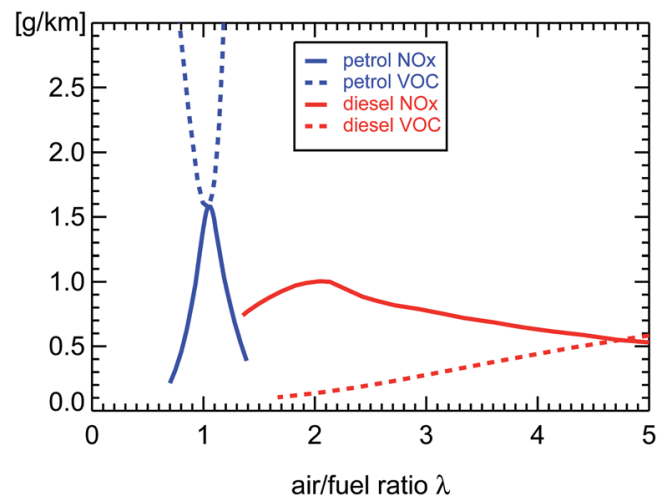

Fig. $3 \mathrm{NO}_{x}$ and $\mathrm{VOC}$ emissions of diesel and petrol passenger cars without catalytic converters; replotted using published mixing ratio measurements (see ref. 6) multiplied with $\lambda$ to be proportional to $\mathrm{g} \mathrm{km}^{-1}$ and then scaled to the values of Table 1 at $\lambda=1$ for petrol and $\lambda=3$ for diesel passenger cars.

converter relies on the exact compliance of a stoichiometrical combustion at $\lambda=1$ and therefore on the use of a $\lambda$-sonde. A little bit on either side of $\lambda=1$ and either NO or CO-VOC are less efficiently converted by the catalyst. When this kind of converter is warm enough, it can reduce VOC and $\mathrm{NO}_{x}$ emissions by actor of 100 (VOC) and $10\left(\mathrm{NO}_{x}\right)$ (see Table 1 and Fig. 4).

Since diesel engines operate at an oxygen excess $(\lambda=3)$, the so called dieseloxidation-catalyst or DOC can only oxidize $\mathrm{CO}$ and $\mathrm{VOC}$ to $\mathrm{CO}_{2}$, but cannot reduce $\mathrm{NO}_{x}$ at the same time. The reduction of CO and VOC by a warm DOC is also a factor of 100 (see Table 1 and Fig. 5). The higher oxygen amount in the exhaust of diesel cars is responsible for a shift of the $\mathrm{NO}_{2} / \mathrm{NO}_{x}$ ratio by the DOC (depending on the catalytic material) towards larger $\mathrm{NO}_{2}$ and smaller $\mathrm{NO}$ concentrations (Fig. 5). In comparison, petrol cars almost exclusively emit NO and only small amounts of $\mathrm{NO}_{2}$.

Table 1 EU emission factors for passenger cars $\left(\mathrm{g} \mathrm{km}^{-1}\right)$

\begin{tabular}{llllll}
\hline & \multicolumn{2}{l}{ Petrol cars } & & \multicolumn{2}{c}{ Diesel cars } \\
\cline { 2 - 3 } \cline { 5 - 6 } Type of car & $\mathrm{NO}_{x}\left(\right.$ as NO $\left._{2}\right)$ & VOC (as HC) & & $\mathrm{NO}_{x}($ as NO \\
\end{tabular}

${ }^{a}$ Date of official implementation of the respective EURO norm. ${ }^{b}$ VOC $+\mathrm{NO}_{x} \cdot{ }^{c}$ Observed values, see Fig. 4 and $5 .{ }^{d}$ See ref. 10. 


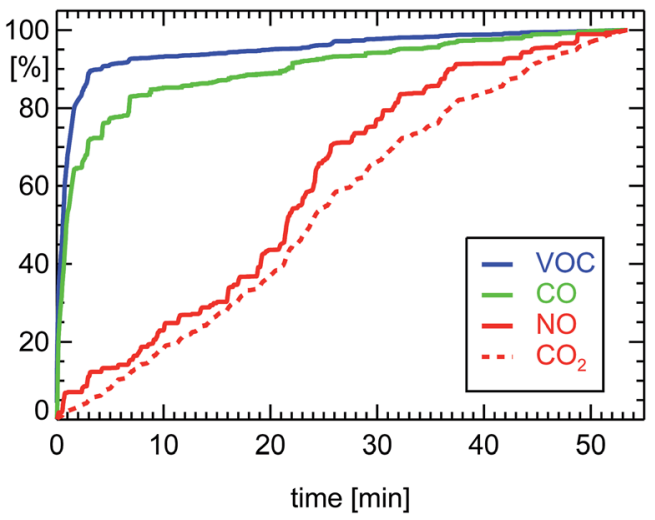

Fig. 4 Normalized cumulative emissions of $\mathrm{CO}(100 \%=23.8 \mathrm{~g}$ corresponding to $0.80 \mathrm{~g}$ $\left.\mathrm{km}^{-1}\right), \mathrm{CO}_{2}\left(262 \mathrm{~g} \mathrm{~km}^{-1}\right)$, NO $\left(0.205 \mathrm{~g} \mathrm{~km}^{-1}\right.$ as $\left.\mathrm{NO}_{2}\right)$, and $\operatorname{VOC}\left(0.088 \mathrm{~g} \mathrm{~km}^{-1}\right.$ as HC) derived during on-board measurements of a petrol car (see ref. 7) during a drive of $29.7 \mathrm{~km}$ length 11.07.2001 in Munich (passenger petrol car, year of manufacture: 2000, 85 kW, GKat, exhaust norm D4).

The efficiency of both kinds of converters, G-Kat and DOC, for the reduction of VOC depends on the temperature of their catalytic material. During the first part of a drive, when engine and converter are at ambient temperature, the converters have to be heated up by the exhaust gas to enable a significant catalytic effect. This warm-up period can last around 1-3 minutes (see Fig. 4 and 5). It is also termed "cold-start condition". At the beginning of this period, the car emits unconverted exhaust. After the warm-up, the full efficiency of the converters is reached, which offers a reduction of emitted VOC by a factor of 100 . For a diesel car, the warmingup period is a little bit shorter than for a petrol car, since the excess of oxygen

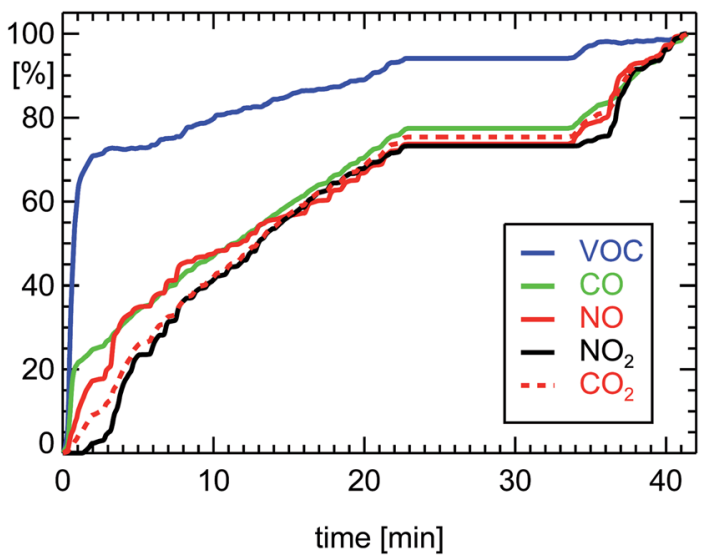

Fig. 5 Normalized cumulative emissions of $\mathrm{CO}(100 \%=2.09 \mathrm{~g}$ corresponding to $0.116 \mathrm{~g}$ $\left.\mathrm{km}^{-1}\right), \mathrm{CO}_{2}\left(180 \mathrm{~g} \mathrm{~km}^{-1}\right)$, NO $\left.\left(0.149 \mathrm{~g} \mathrm{~km}^{-1} \text { as NO}\right)_{2}\right), \mathrm{NO}_{2}\left(0.173 \mathrm{~g} \mathrm{~km}^{-1}\right)$, and VOC $(0.008 \mathrm{~g}$ $\mathrm{km}^{-1}$ as $\mathrm{HC}$ ) derived during measurements of a diesel car (see ref. 7) during a drive of 18.0 $\mathrm{km}$ length 27.11.2002 executing a FTP-75-cycle (passenger diesel car, year of manufacture: 2002, $105 \mathrm{~kW}$, DOC, exhaust norm EURO3). 
favors the oxidation of VOC by a DOC. Taken together, the effective reduction of VOC for the full stretch of a 50 min drive which begins with a cold converter is approximately a factor of 10 for petrol and 30 for diesel passenger cars equipped with G-Kat or DOC, respectively. The situation is different when the converters are already warm at start-up. In this case, the converters are acting with full efficiency for the whole drive.

The efficiency of a G-Kat for $\mathrm{NO}_{x}$ reduction does not depend too much on the temperature of the converter (see Fig. 4). That seems to be against expectations. But one has to take into account the fact that during the warm-up period CO and VOC are not removed by the catalytic material so the reaction of NO with CO is favored by the large concentration of CO during that period of low temperature (see for example ref. 14). Later, when the catalytic material heats up, CO is removed but, on the other hand, the efficiency of the catalyst for the reduction of $\mathrm{NO}$ is growing. As a consequence, the removal of $\mathrm{NO}_{x}$ from the exhaust gas of a petrol car by a G-Kat seems not to have a significant warm-up period. But this overall reduction for $\mathrm{NO}_{x}$ is smaller than the potential reduction for VOC at optimal conditions. As a consequence, taking into account the warming-up period, the overall reduction efficiency of a G-Kat is a factor of 10 both for $\mathrm{NO}_{x}$ and for VOC for a petrol car. For a diesel car, the overall VOC reduction is a factor of 30. Since the initial VOC emission of the diesel engine before entering the DOC is ten times smaller than that of a petrol engine, a diesel passenger car emits approximately a factor of 30 less VOC than a petrol car during a drive inside a city district.

The $\mathrm{NO}_{x}$ emissions of petrol cars seem to be in accordance with EU regulations $^{11,12}$ (see Table 2). This is different for diesel cars. They show a significant inconsistency between allowed emission factors and real-world observations. ${ }^{11,12}$ The real-world $\mathrm{NO}_{x}$ emissions of a diesel car today seem to be the same as 30 years ago (see Table 2). Together with the growing number of diesel cars with respect to the total number of passenger cars in Germany, the fraction of $\mathrm{NO}_{x}$ emissions of diesel cars relative to all passenger cars in Germany is estimated to be around $85 \%$ in the year 2015 (estimated from Table 3). Therefore, taking into account

Table $2 \mathrm{NO}_{x}$ Real Drive Emissions (RDE) for passenger cars ${ }^{11,12}\left(\mathrm{~g} \mathrm{~km}^{-1}\right)^{a}$

\begin{tabular}{|c|c|c|c|c|c|c|c|c|}
\hline \multirow{2}{*}{$\begin{array}{l}\text { Exhaust norm } \\
\text { of car }\end{array}$} & \multicolumn{4}{|c|}{ Petrol cars $\left(\mathrm{g} \mathrm{km}^{-1}\right)^{a}$} & \multicolumn{4}{|c|}{ Diesel cars $\left(\mathrm{g} \mathrm{km}^{-1}\right)^{a}$} \\
\hline & $\mathrm{CO}_{2}{ }^{b}$ & $\mathrm{RDE}^{c}$ & $\mathrm{EU}^{d}$ & HBEFA $^{e}$ & $\mathrm{CO}_{2}{ }^{b}$ & $\mathrm{RDE}^{c}$ & $\mathrm{EU}^{d}$ & HBEFA $^{e}$ \\
\hline None & 228 & 2.38 & & 1.22 & 186 & 1.04 & & 0.97 \\
\hline EURO-1 ${ }^{f}$ & 212 & 1.15 & & 0.47 & 181 & 0.98 & & 0.97 \\
\hline EURO- $2^{f}$ & 204 & 0.74 & & 0.33 & 171 & 0.94 & & 1.02 \\
\hline EURO- $3^{f}$ & 193 & 0.22 & 0.15 & 0.10 & 158 & 1.12 & 0.50 & 0.98 \\
\hline EURO- $4^{f}$ & 178 & 0.08 & 0.08 & 0.10 & 152 & 0.96 & 0.25 & 0.85 \\
\hline EURO- $5^{f}$ & 159 & 0.06 & 0.06 & 0.05 & 136 & 1.12 & 0.18 & 0.84 \\
\hline EURO- $\sigma^{f}$ & 143 & & 0.06 & 0.05 & 122 & & 0.08 & 0.84 \\
\hline EURO- $6 \mathrm{c}^{g}$ & & & & 0.05 & & & 0.08 & 0.14 \\
\hline
\end{tabular}

${ }^{a} \mathrm{NO}_{x}$ taken as $\mathrm{NO}_{2} .{ }^{b}$ UK emission factor estimates. ${ }^{11}{ }^{c}$ Observed values in London by the RSD technique. ${ }^{11}{ }^{d} \mathrm{EU} \mathrm{NO} \mathrm{N}_{x}$ emission factors for passenger cars. ${ }^{e}$ HBEFA 3.2 (ref. 12) observed $\mathrm{NO}_{x}$-emissions for CADC urban drive cycle. ${ }^{f}$ EURO exhaust norm. ${ }^{9}{ }^{g}$ EURO-6c expected value in HBEFA 3.2. ${ }^{12}$ 
Table 3 Ratio of the $\mathrm{NO}_{x}$ emissions for diesel/petrol passenger cars in Germany (estimated using real world observations, see ref. 11); the emissions of heavy-duty-cars are not included

\begin{tabular}{lccc}
\hline $\begin{array}{l}\text { Exhaust norm } \\
\text { of car }\end{array}$ & Year & $\begin{array}{l}\text { DPC } /(\mathrm{DPC}+\mathrm{PPC})^{a} \\
\text { For number }^{b}[\%]\end{array}$ & $\begin{array}{l}\mathrm{DPC} /(\mathrm{DPC}+\mathrm{PPC})^{a} \\
\text { For NO }_{x} \text { emissions }^{c}[\%]\end{array}$ \\
\hline None & 1980 & 5 & 2.2 \\
EURO-1 $^{d}$ & 1993 & 13.5 & 10.3 \\
EURO-2 $^{d}$ & 1997 & 13.8 & 14.9 \\
EURO-3 $^{d}$ & 2001 & 13.9 & 41.5 \\
EURO-4 $^{d}$ & 2006 & 21.9 & 72.4 \\
EURO-5 $^{d}$ & 2011 & 26.6 & 83.2 \\
EURO-6 $^{d}$ & 2015 & 31.2 &
\end{tabular}

${ }^{a}$ DPC - diesel passenger cars, PPC - petrol passenger cars. ${ }^{b}$ Inventory of passenger cars in Germany; ${ }^{13}$ see Fig. $6 .{ }^{c}$ Calculated from Table 2 (ref. 11) and from column 3, this table. ${ }^{d}$ EURO exhaust norm. ${ }^{9}$

some heavy duty diesel vehicles, we can safely expect that the $\mathrm{NO}_{x}$ concentrations in German inner city districts in the last ten years were dominated by the emissions of diesel cars. In the year 1994, the situation was different. At that time, the majority of passenger petrol cars were not yet equipped with a G-Kat (see Fig. 8). Hence, the small number of diesel cars together with the basically lower $\mathrm{NO}_{x}$ emissions of diesel engines caused a low contribution of diesel cars to the $\mathrm{NO}_{x}$ concentrations in inner city districts in Germany.

\subsection{Composition and emissions of the car fleet in Germany}

The number of passenger cars in Germany rose from 32 million to 43 million cars in the time interval 1994-2014, if one accounts for some temporarily suspended/ decommissioned cars in the numbers before 2008 (see Fig. 6). During the same time, the fraction of diesel cars increased ${ }^{13}$ from $13.7 \%$ to $30.1 \%$.

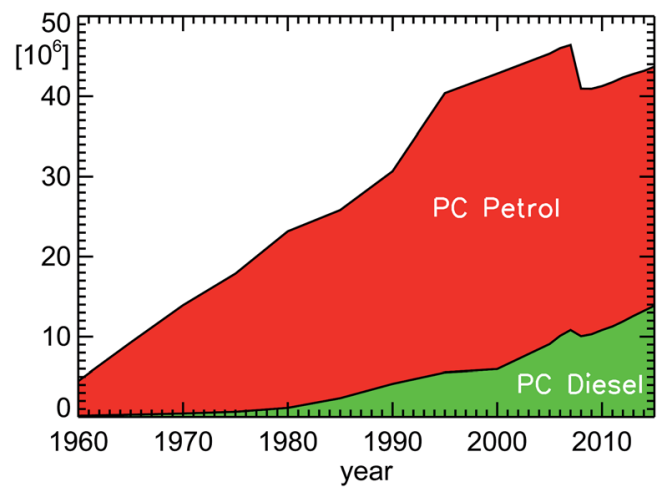

Fig. 6 Inventory of passenger cars (PC diesel and PC petrol) in Germany for the years 1960-2015 (see ref. 13); since January 1, 2008, only active vehicles are taken into account without counting temporary suspended or decommissioned cars. 
If one wants to approach an estimate for $\mathrm{NO}_{x}$ and VOC emissions, one also has to take into account the average number of kilometers for each type of car (petrol or diesel car, passenger or heavy-duty car). This is not explicitly shown here, but reflected in the amount of fuel used by each class of cars (see Fig. 7). Another important boundary condition is the pollution classification of individual cars ${ }^{\mathbf{1 5}}$ (see Fig. 8) which also depicts the average lifespan of a technology change within the car fleet in Germany. Approximately 8 years after the implementation of a new pollution classification, half of the passenger car fleet still has the old classification.

If one takes suitable emission factors for $\mathrm{NO}_{x}$ and VOC for each pollution classification (see Table 1), one can estimate the amount of $\mathrm{NO}_{x}$ and VOC emitted by road traffic in Germany for each year (see Fig. 9, 10a and b). The shown inventories use emission factors called "HBEFA 3.1". ${ }^{16}$ Astonishingly enough, these emission factors used to calculate the emission inventories are taken from observations at least since the year 2009 and are called "Real Drive Emissions"

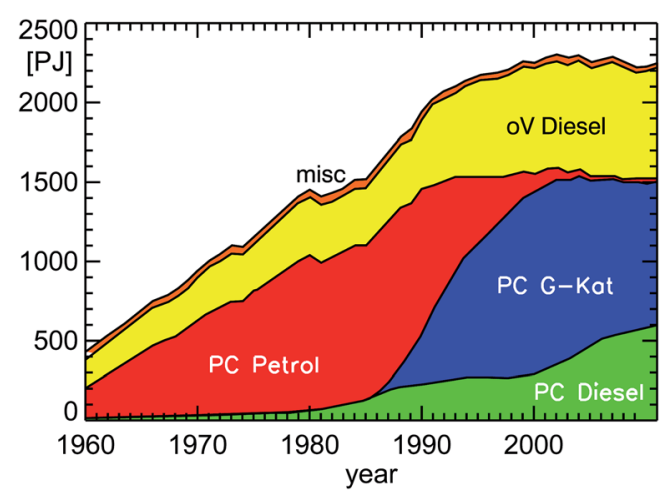

Fig. 7 Annual fuel consumption of road traffic in Germany for the years 1960-2011 (PC: passenger cars; oV: other vehicles including HGV, LCV, and bus (Heavy Goods Vehicles, Light Commercial Vehicles, buses); misc: miscellaneous petrol cars; natural and liquefied gas included in PC petrol; PJ: Peta Joule ( $=10^{15}$ Joule); replotted from TREMOD version 5.3 (see ref. 15)).

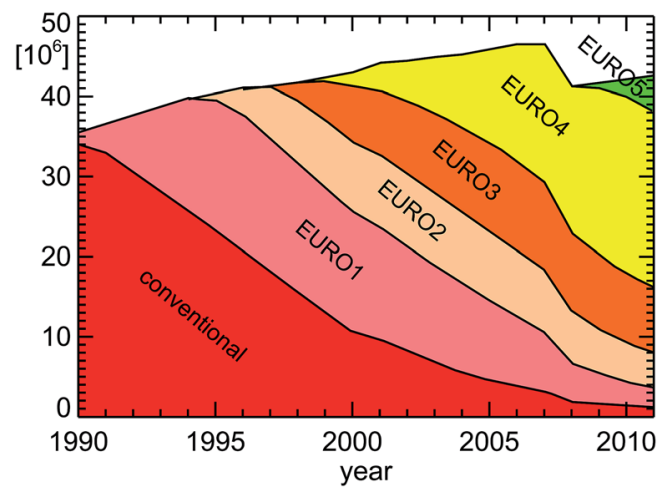

Fig. 8 Vehicle emission regulation categories for passenger cars in Germany for the years 1990-2011; replotted from TREMOD version 5.3 (see ref. 15 and Table 1). 
(RDE). It appears that the current public discussion of the discrepancy between real world emissions and EU norm emissions (see for example Table 2) is already implemented into those emission estimates by using $\mathrm{NO}_{x}$ emission factors

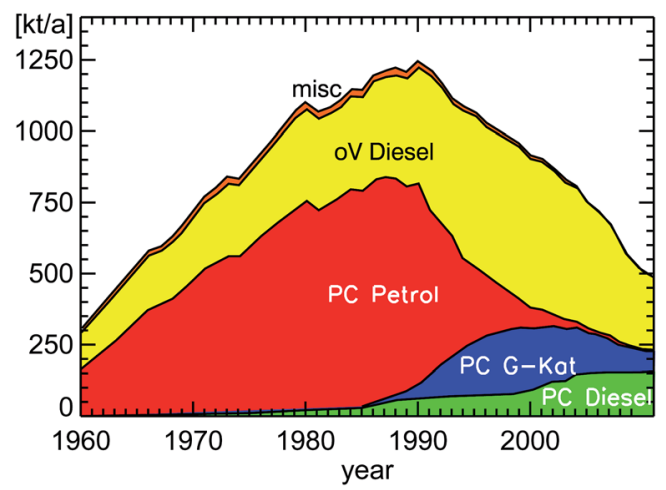

Fig. $9 \mathrm{NO}_{x}$ emissions (as $\mathrm{NO}_{2}$ ) of road traffic in Germany for the years 1960-2011 (PC: passenger cars; OV: other vehicles including HGV, LCV, and bus (Heavy Goods Vehicles, Light Commercial Vehicles, buses); misc: miscellaneous petrol cars and remaining types of road traffic); replotted from TREMOD version 5.3 (see ref. 15).

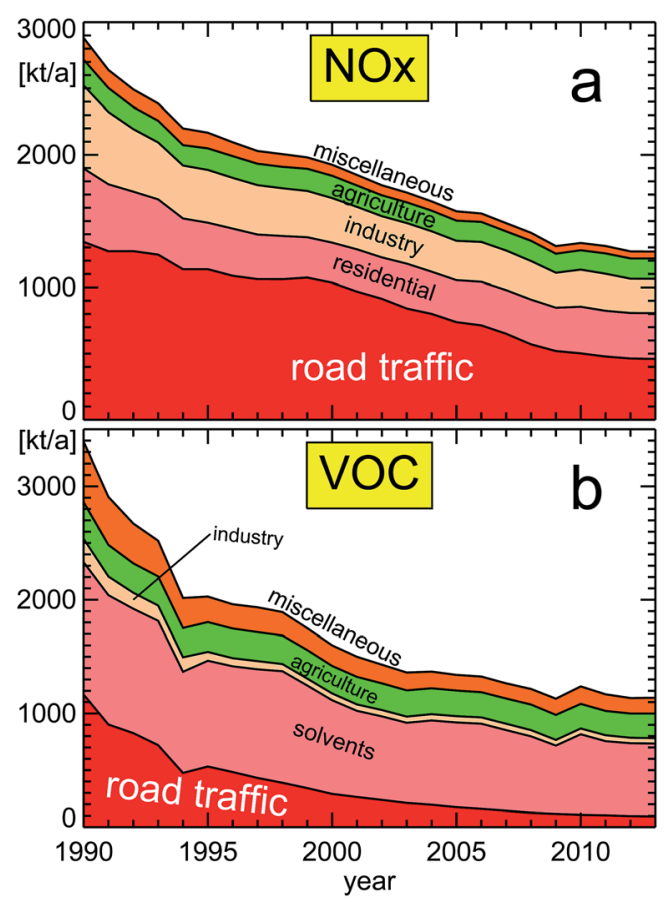

Fig. $10 \quad \mathrm{NO}_{x}$ (panel a) and $\mathrm{VOC}$ (panel b) emissions for different source categories (VOC without methane; replotted from a publication of the German Federal Environmental Agency $U B A^{18}$ ); featured categories from bottom to top: (a) road traffic, residential, industry, agriculture, miscellaneous, and (b) road traffic, solvents, industry, agriculture, miscellaneous. The composition of the different categories is shown in Section 6. 
around $0.8 \mathrm{~g} \mathrm{~km}^{-1}$ for all diesel passenger cars. ${ }^{17}$ The intrinsic assumption in the following considerations is the expectation that the trend of concentrations in inner city districts will follow the trend of suitable emissions categories for the whole of Germany.

1.3.1 $\mathrm{NO}_{x}$ emissions in urban areas in Germany. For $\mathrm{NO}_{x}$, one can compare the estimated emission inventories to observed concentrations, for example observations from inner city districts. If we focus on the time period 1995-2008, the estimated $\mathrm{NO}_{x}$ reduction by road traffic emissions in Fig. 10a is a factor of 1.9 in 13 years $=2.9$ in 20 years. The observed trend of $\mathrm{NO}_{x}$ concentrations in inner city districts in Fig. 11 is a factor of 1.6 in 13 years $=2.4$ in 20 years. That is close, but it might be coincidental. For example, the traffic in inner city districts contains a smaller proportion of heavy-goods-vehicles (HGV) and proceeds at a slower speed compared to highways and out-of-town traffic which all contribute to the total traffic emissions in Germany as shown in Fig. 10a. But the information at hand $\left(\right.$ TREMOD $^{15}$ and HBEFA ${ }^{16}$ ) gives enough parameters to try to make a better estimate for $\mathrm{NO}_{x}$ emissions in inner city districts ourselves.

If we take the published annual traveling distance of passenger cars (PC) in inner city districts in Germany of around $160 \times 10^{9} \mathrm{~km} \mathrm{a}^{-1}$ (Fig. 12), the ratio of diesel to petrol passenger cars (Fig. 6), the emission regulation categories for passenger cars (Fig. 8), and the observed emission factors in London from Table 2, we can estimate the annual $\mathrm{NO}_{x}$ emissions of passenger cars in inner city districts of Germany (Fig. 13).

We then have to add the amount of $\mathrm{NO}_{x}$ emitted by heavy-goods-vehicles (HGV) and light-commercial-vehicles (LCV) by using the same kind of parameters for the traveling distance in inner city districts ${ }^{15}$ (around $8 \times 10^{9} \mathrm{~km} \mathrm{a}^{-1}$ for HGV and $17 \times 10^{9} \mathrm{~km} \mathrm{a}^{-1}$ for LCV in 2010). All HGV and 93\% of the LCV vehicles have a diesel engine. ${ }^{15}$ The emission factor for these vehicles is estimated for a speed of $25 \mathrm{~km} \mathrm{~h}^{-1}$ to be $10 \mathrm{~g} \mathrm{~km}^{-1}$ for HGV and $1 \mathrm{~g} \mathrm{~km}^{-1}$ for diesel-LCV. ${ }^{16}$ For simplicity we take $100 \%$ of LCV as diesel vehicles. The large emission factors for HGV at low speeds are explained in HBEFA 3.2:12 "EURO V with SCR: the $\mathrm{NO}_{x}$ output in medium and high average engine loads (e.g. motorway and rural driving situations) is low. In contrast, $\mathrm{NO}_{x}$ emission factors are close to EURO III in urban

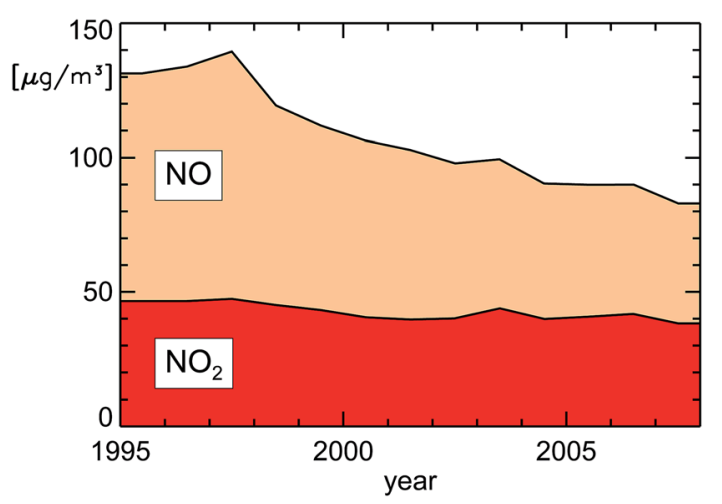

Fig. 11 Annually averaged $\mathrm{NO}_{x}$ concentrations ( $\mathrm{NO}$ displayed as $\mu \mathrm{g} \mathrm{m}^{-3} \mathrm{NO}_{2}$ ) close to traffic in inner city districts in Germany (replotted from UBA ${ }^{19}$ ). 


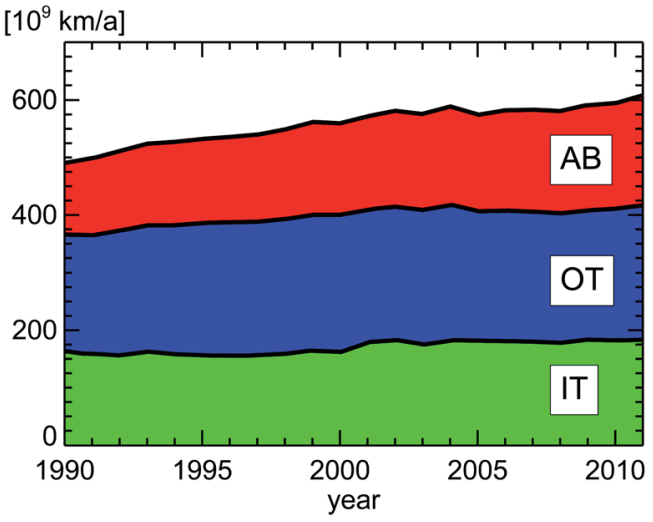

Fig. 12 Vehicle kilometers traveled by passenger cars in Germany; replotted from TREMOD version 5.3. ${ }^{15}$ AB: Autobahn, OT: out-of-town, IT: in-town.

driving and in stop-and-go conditions due to low $\mathrm{DeNO}_{x}$-performance of EURO V SCR after treatment in the low exhaust gas temperature range". Other categories for road traffic in urban areas (apart from "PC", "LCV", and "HGV") are not included because ref. 15 does not contain information about them. As a hint one can take ref. 20 which provides projected information for 2015. The vehicles within the categories "Bus", "Motorcycles", and "Vans" there have traveling distances in urban areas of $1.64,5.31$, and $2.85 \times 10^{9} \mathrm{~km} \mathrm{a}^{-1}$, respectively. The associated $\mathrm{NO}_{2}$ emissions are 6.66, 0.77 , and $2.34 \mathrm{kt} \mathrm{a}^{-1}$ which yield average emission factors of $4.1,0.15$, and $0.82 \mathrm{~g} \mathrm{~km}^{-1} \mathrm{NO}_{2}$. Taking these numbers, approximately $10 \mathrm{kt} \mathrm{a}^{-1}$ or $6 \% \mathrm{NO}_{2}$ would be missing in Fig. 13 around the year 2015.

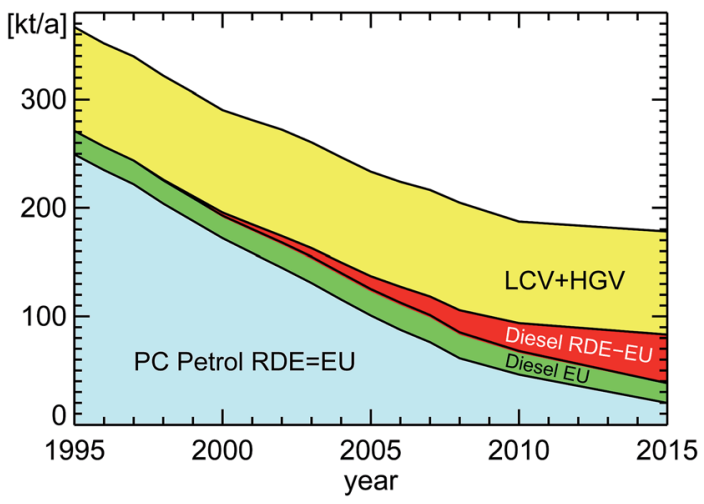

Fig. 13 Estimated $\mathrm{NO}_{x}$ traffic emissions in urban areas in Germany, this paper; for details see subsection 1.3.1. Featured categories from bottom to top are: "PC petrol RDE $=E U^{\prime}$ ": PC petrol car emissions which essentially show real-drive-emissions RDE in compliance with EU legislation, "PC diesel EU": intended PC diesel car emissions according to EU legislation, "PC diesel RDE-EU": surplus of PC diesel car real-drive-emissions RDE on top of the intended emissions according to EU legislation, "LCV + HGV": emissions of lightcommercial-vehicles and of heavy-goods-vehicles. For other categories see text. 
The final result in Fig. 13 shows the significant contribution of HGV and LCV diesel vehicles to the total amount of traffic $\mathrm{NO}_{x}$ emissions in urban areas in Germany, a point which already emerged from the published emission inventory for the whole of Germany in Fig. 9. The difference between real-world-emissions (RDE) and EU-norm-emissions (EU) for petrol passenger cars is very small and therefore cannot be seen in Fig. 13. That is entirely different for diesel passenger cars. As expected, there is a large discrepancy between real-world-emissions (RDE) and EU-norm-emissions (EU) for diesel passenger cars. Overall, the relative amount of $\mathrm{NO}_{x}$ emissions diesel passenger cars add up due to their noncompliance with EU regulations is estimated to be on the order of $25 \%$ for the year 2015 for Germany.

To test our simple approach we expanded the estimate for $\mathrm{NO}_{x}$ traffic emissions to the whole of Germany by adding portions for "out-of-town" and "Autobahn" of the different kinds of vehicles. For these situations we had to take a lower emission factor of $2.5 \mathrm{~g} \mathrm{~km}^{-1}$ for HGV allowing for the faster speed (see above). The total estimated $\mathrm{NO}_{x}$ traffic emission for the year 2012 is $467 \mathrm{kt} \mathrm{a}^{-1}$ from our simple approach. The published result from Fig. 10a is $463 \mathrm{kt} \mathrm{a}^{-1}$ in 2012, very close to our estimate. However, this good agreement should not obscure the simplicity of our approach. Another test of our estimate can be obtained from ref. 11, Table 5. This publication reports ratios of $26 \%, 25 \%, 26 \%$, and $23 \%$ of $\mathrm{NO}_{x}$ RDE-emissions for the fleet of diesel PC, petrol PC, LCV, and HGV (including buses), respectively, encountered during campaigns in 2007-2010 in London, UK, quite comparable to Fig. 13. And the authors of this publication ${ }^{\mathbf{1 1}}$ explicitly state that their estimates "better reflect urban areas" than a national total.

The total decrease of $\mathrm{NO}_{x}$ emissions between the years 1995-2008 in Fig. 13 is a factor of 1.9 in 13 years $=2.9$ in 20 years, or, directly using the years 1995-2015, it is a factor of 2.1 in 20 years. That is quite comparable to the observed trend of $\mathrm{NO}_{x}$-concentrations in inner city districts in Germany (see Fig. 11). This analysis also confirms that the amount of diesel engine exhaust (HGV $\left.+\operatorname{LCV}_{\text {diesel }}+\mathrm{PC}_{\text {diesel }}\right)$ is expected to have a fraction of $90 \%$ with respect to $\mathrm{NO}_{x}$ traffic emissions in urban areas in Germany in the year 2015.

1.3.2 VOC emissions in urban areas in Germany. The situation is different for the VOC trend. First of all, we have no comprehensive data basis for observed VOC concentrations like for $\mathrm{NO}_{x}$ since VOC measurements are more demanding. Second, we have to deal with the dominating category of VOC emissions in the published inventory for Germany (see Fig. 10), the "solvents". These are VOCs which are emitted by spilling and evaporation from industrial sources, for example through degreasing of components using light petrol. In Germany, industrial zones are very often close to cities, so one would anticipate to find the VOC-fingerprint of the largest source category everywhere, thus in air samples from city districts too. As we show afterwards, significant concentrations are not found in ambient observations, neither in cities nor elsewhere (see also ref. 21). To give a more quantitative measure for this, the observed concentrations of solvents are less than $10 \%$ of the total VOC concentration in inner city districts. One would have to go very near to the industrial facilities to clearly detect the fingerprints of solvents. ${ }^{21}$ This is astonishing, since the atmospheric lifetimes of the individual solvent species are on the order of days or weeks. That means, on the other hand, that their reactivity contribution will be very much less than $10 \%$ 
which is the upper limit for their mass contribution. We therefore exclude the category "solvents" from the following considerations which aim at the air mass composition in inner city districts. If we only look at the trend of "road traffic" VOC-emissions, we see a reduction of a factor of 7.3 in 20 years. The other VOC emission categories do not seem appropriate ("agriculture") or are too small ("industry"). From these considerations, the emission inventories would suggest the trend of the $\mathrm{VOC} / \mathrm{NO}_{x}$ mass ratio in inner city districts to be 7.3 in 2.5 years = 2.9 in 1 year for the time period 1994-2014.

\section{Experimental}

Measurements of VOCs and $\mathrm{NO}_{x}$ were conducted over a period of the last 20 years. Only the technical fundamentals will be described in the following. Individual conditions and optimization steps can be found in the listed references.

\subsection{VOC detection}

The gas chromatographic system for analyzing ambient air samples was developed in the late nineties ${ }^{22}$ and has been continuously optimized and upgraded. In this context the current state of the system will be described.

The gas chromatographic system is based on a conventional gas chromatograph (Agilent 6890) which is equipped with a flame-ionization detector (FID) for the quantification, and with a mass-spectrometer (Agilent 5975C MSD) for the identification of the VOCs. To analyze concentrations at trace-gas level, a cryogenic pre-concentration system was developed, consisting of a sample loop (Silcosteel, $20 \mathrm{~cm}$ length, inner diameter $2 \mathrm{~mm}$, packed with $0.25 \mathrm{~mm}$ glass beads) which was cooled down in the cold gas above liquid nitrogen (see Fig. 14). In the standard operation procedure, a volume of $800 \mathrm{~mL}$ was pre-concentrated in the

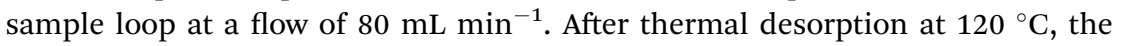
sample was injected on a capillary column (type "DB-1", $120 \mathrm{~m}$ length, $0.32 \mathrm{~mm}$ inner diameter, $3 \mu \mathrm{m}$ film thickness) at a temperature of $-60^{\circ} \mathrm{C}$. The GC-oven was kept at $-60^{\circ} \mathrm{C}$ for $8 \mathrm{~min}$, heated to $180^{\circ} \mathrm{C}$ at a rate of $4{ }^{\circ} \mathrm{C} \mathrm{min}{ }^{-1}$, then heated to $220{ }^{\circ} \mathrm{C}$ at a rate of $20^{\circ} \mathrm{C} \mathrm{min}{ }^{-1}$, and kept isothermal at $220^{\circ} \mathrm{C}$ for $10 \mathrm{~min}$. At the end of the capillary column, the carrier stream was split and fed towards the FID

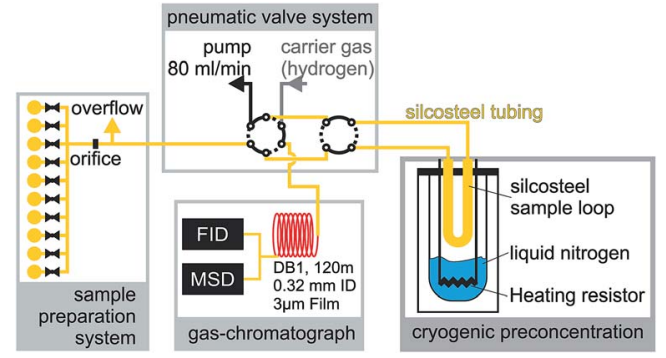

Fig. 14 Schematic overview of the gas chromatographic system optimized for VOC analysis ranging from trace level concentrations to exhaust concentrations consisting of a canister manifold, pneumatic valves, and a cryogenic preconcentration unit. The current setup allows the analysis of up to 10 canisters in unattended operation. 
and MSD detectors. A typical FID chromatogram is shown in Fig. 15. The identification and quantification of the VOCs as well as routine checks for sensitivity by comparison to calibration reference standards (Apel-Riemer Environmental Inc., Denver, CO, USA) were performed in regular intervals. Overall, the precision of quantification was 5-6\% and the limit of detection was 5-15 ppt (varying for the different VOC species ${ }^{23}$ ).

Using the previously described setup, online in situ measurements of VOCs were also performed aboard the mobile Laboratory-truck of the FZJ. ${ }^{22,24-26}$ In other cases, when in situ measurements were not possible (e.g. measurements in a forest ${ }^{27}$ to inspect biogenic emissions or measurements while driving on-road to inspect traffic emissions ${ }^{23,28}$ ), air samples were collected in evacuated Silcosteel canisters (SilcoCan, Restek).

If necessary, ozone was removed by a heated Silcosteel capillary prior to sampling into the cylinders. The canisters were then pressurized with synthetic air to reduce the relative humidity of the sample and hence possible water-

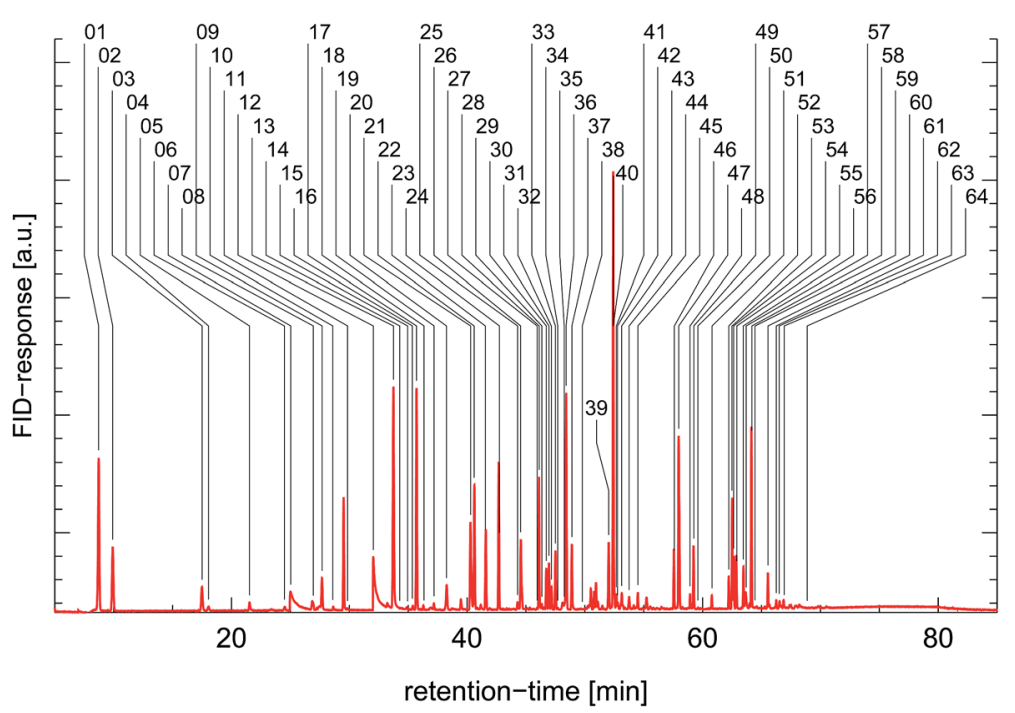

Fig. 15 Characteristic chromatogram from a cold petrol car. The peaks are labeled as follows: 01 - ethene; 02 - ethane; 03 - propene; 04 - propane; 05 - propyne; 06 methylpropane; 07 - methanol; 08 - 1-butene/i-butene; 09 - $n$-butane; 10 - trans-2butene; 11 - cis-2-butene; 12 - ethanol; 13 - 2-methylbutane; 14 - acetone; 15 - 1pentene; 16 - 2-propanol; 17 - $n$-pentane; 18 - isoprene; 19 - cis-2-pentene; 20 - 2,2dimethylbutane; 21 - cyclopentane/2,3-dimethylbutane; 22 - 2-methylpentane; 23 - 3methylpentane; 24 - $n$-hexane; 25 - trans-1,3-hexadiene; 26 - methylcyclopentane/2,4dimethylpentane; 27 - methylcyclopentene; 28 - benzene; 29 - 1-butanol; 30 cyclohexane; 31 - 2-methylhexane; 32 - 2,3-dimethylpentane; 33 - 3-methylhexane; 34 - pentanal; 35 - 1-heptene; 36 - 2,2,4-trimethylpentane; 37 - heptane; 38 - 2,3dimethyl-2-pentene; 39 - 2,3,4-trimethylpentane; 40 - toluene; 41 - 2-methylheptane; 42 - 4-methylheptane; 43 - 3-methylheptane; 44 - hexanal; 45 - n-octane; 46 - ethylbenzene; 47 - $m / p$-xylene; 48 - styrene; 49 - o-xylene; 50 - $n$-nonane; 51 - i-propylbenzene; 52 - $n$-propylbenzene; 53 - $m$-ethyltoluene; $54-p$-ethyltoluene; 55 1,3,5-trimethylbenzene; 56 - o-ethyltoluene; 57 - octanal; 58 - 1,2,4-trimethylbenzene/ t-butylbenzene; 59 - $n$-decane; 60 - 1,2,3-trimethylbenzene; 61 - indane; 62 - 1,3diethylbenzene; 63 - 1,4-diethylbenzene/butylbenzene; 64 - $n$-undecane. 
interferences in the FID detector. The pressurized canisters were then connected to the canister manifold at the GC-system which allows the unattended analysis of up to 10 canisters at a time (see Fig. 14). Quantification was then performed using the same routines as for the in situ measurements.

The suitability of the Silcosteel canisters for VOC sampling and storage of humid samples for up to two days was extensively scrutinized and the stability of their content confirmed. ${ }^{29}$ To analyze the VOC-composition in the exhaust of petrol- and diesel-vehicles, the gas was diluted with synthetic air prior to sampling in the canisters and then analyzed using the same gas-chromatographic system as for the ambient measurements. ${ }^{7,28,30,31}$ If very high concentrations had to be expected, the sampling volume in the pre-concentration unit was limited to $80 \mathrm{~mL}$ to prevent overloading of the system.

The total hydrocarbon concentration in the exhaust of the different vehicles was analyzed with a commercially available total organic carbon detector (TOC; MICRO-FID 100, ABB Corp.) which is basically a flame-ionization-detector without a gas-chromatographic system in front of it., ${ }^{7,28,30}$

\section{$2.2 \mathrm{NO}_{x}$ detection}

$\mathrm{NO}_{x}$-measurements in ambient air samples were based on the principle of chemiluminescence: NO reacts with ozone to an excited $\mathrm{NO}_{2}$ molecule. Photons emitted during radiative disexcitation can then be detected by a photomultiplier and used for the quantification of the concentration of $\mathrm{NO} \cdot{ }^{32,33} \mathrm{NO}_{2}$ was detected after conversion to NO using either a molybdenum converter ${ }^{22,24}$ or a photolytic converter. $^{23,25,28}$

To analyze the $\mathrm{NO}_{x}$-concentrations in the exhaust of petrol- and diesel-vehicles, commercially available analyzers (LIMAS11, ABB corp.) based on UVabsorption were used. ${ }^{7,28,31}$

\section{Results}

\subsection{Ambient observations}

For the following considerations we will use $\mathrm{NO}_{x}$ and VOC observations not in the usual manner as concentrations or mixing ratios, but as reactivities. Reactivity denotes the reaction speed of a substance or of a group of substances with the $\mathrm{OH}$ radical, the principal agent in the photochemical production of ozone. The eminent significance of $\mathrm{OH}$ radicals within tropospheric chemistry is justified since during daytime more than $90 \%$ (ref. 1 and 34) of all VOC react with $\mathrm{OH}$ radicals.

Reactivity is expressed as reciprocal lifetime of $\mathrm{OH}$ in a certain reaction and has the unit $\mathrm{s}^{-1}$. For example, VOCs are oxidized by $\mathrm{OH}$ to form more oxidized species. The final product of such an $\mathrm{OH}$-oxidation pathway starting with VOC is, after several steps, $\mathrm{CO}_{2}$. The important point here is that in each VOC-oxidation step ozone is produced as a by-product in the presence of nitrogen oxides, specifically in the presence of $\mathrm{NO}$. The other nitrogen oxide species, $\mathrm{NO}_{2}$, is also oxidized by reaction with $\mathrm{OH}$ to $\mathrm{HNO}_{3}$ without producing ozone like VOCs. The reactivity of a certain $\mathrm{NO}_{2}$ concentration, $R_{\mathrm{NO}_{2}}$, can be calculated by multiplying the concentration value with the rate constant of the reaction of $\mathrm{NO}_{2}$ with $\mathrm{OH}$, $k_{\mathrm{OH}+\mathrm{NO}_{2}}: R_{\mathrm{NO}_{2}}=k_{\mathrm{OH}+\mathrm{NO}_{2}} \times\left[\mathrm{NO}_{2}\right]$. The same can be done for a specific $\mathrm{VOC}_{i}$ 
substance: $R_{\mathrm{VOC}_{i}}=k_{\mathrm{OH}+\mathrm{VOC}_{i}} \times\left[\mathrm{VOC}_{i}\right]$. The sum of all individual $\mathrm{VOC}_{i}$ then gives the total VOC reactivity $R_{\mathrm{VOC}}$. The individual rate constant parameterizations are taken from the literature ${ }^{35,36}$ or from the chemical reaction mechanism MCM$3.1{ }^{37}$ which is later-on also used to derive ozone production estimates for different air masses. For all reactivities shown in this paper we used a reference temperature of $298 \mathrm{~K}$ for input to the rate constant parameterizations. This has been done to ensure consistency with the ozone production approach discussed in Section 4.2. We note here, that the averaged ratio of the individual rate constants $k_{\mathrm{OH}+\mathrm{VOC}_{i}} / k_{\mathrm{OH}+\mathrm{NO}_{2}}$ for a typical traffic VOC mix is temperature dependent with a slope of $10 \%$ per $10 \mathrm{~K}$.

VOCs are typically measured using a gas-chromatographic system (GC). The single $\mathrm{VOC}_{i}$ are separated by such a GC-system and reach the detector at a specific time after injection of the gas sample, the so-called retention time. The retention time is only dependent on the physical properties of the individual $\operatorname{VOC}_{i}$ and on the GC system used. For a specific GC system, the retention times for the different substances are known by using reference air samples. The operator then transposes the raw signals of the different species, which establish the so-called chromatogram, into concentrations of the individual species and records their name and concentration in the form of a table. From this table one can then calculate the individual reactivity contributions of the individual $\operatorname{VOC}_{i}$-species and add them up to obtain the total VOC reactivity, $R_{\mathrm{VOC}}$. One can also transpose the original chromatogram showing raw signals into a chromatogram which shows peaks scaled to the reactivity of the different species. This is done by taking a Gaussian standard peak (which has an appropriate peak-width typical for the utilized GC-system), scale its maximum with the reactivity of a certain $\operatorname{VOC}_{i}$ and then add this synthetic Gaussian peak to a baseline data vector at the position of the retention time of that specific $\mathrm{VOC}_{i}$. The appearance of such a reactivitychromatogram is very different to the original chromatogram, because this technique emphasizes those VOC-species which are responsible for ozone production instead of showing a composition related to mass (FID raw signals are primarily related to the carbon atom content of the molecules). For that reason we will use these synthesized reactivity chromatograms (SRC) throughout this paper which still hold the look-and-feel of the original chromatograms and allow for a fast visual impression of the VOC-composition of an air sample. These SRCs will be used in a standardized form, that means they are divided by the largest occurring value in each particular chromatogram. The use of SRCs and the standardization procedure have the additional benefit of allowing comparison to different published VOC-patterns, if the species names and their concentrations are known from the publication (see Fig. 24).

3.1.1 VOC fingerprints. To show the specificity of GC patterns for individual sources we present reactivity chromatograms for a range of source situations and ambient observations. The look of such a chromatogram with its different peak positions and peak heights is called the "fingerprint". Since there might be hundreds of different $\mathrm{VOC}_{i}$ in a chromatogram, there are millions of different fingerprints possible. Fortunately, if one takes samples directly at the exhaust pipes of different cars, it is obvious that the engine type of a car generates a specific fingerprint which is very similar for cars of that engine type. There are slight differences from car-to-car, but the similarities between chromatograms of a certain engine type are striking. So those fingerprints, when known, can be used 
to determine the contribution of a certain type of car within a chromatogram of an ambient air sample. For example, measuring a large number of petrol cars, two kinds of fingerprints can be derived: the fingerprints for the cold-start and warm conditions of the car. These are clearly distinguishable from each other and from those of diesel cars as shown in Fig. 16-19.

It is important to note here that other sources for VOCs in ambient air masses have quite different but at the same time very specific fingerprints, for example the fingerprints of diesel fuel or of petrol fuel (both not shown here). The fingerprint from a forest site in Fig. 20 contains a single dominant peak caused by

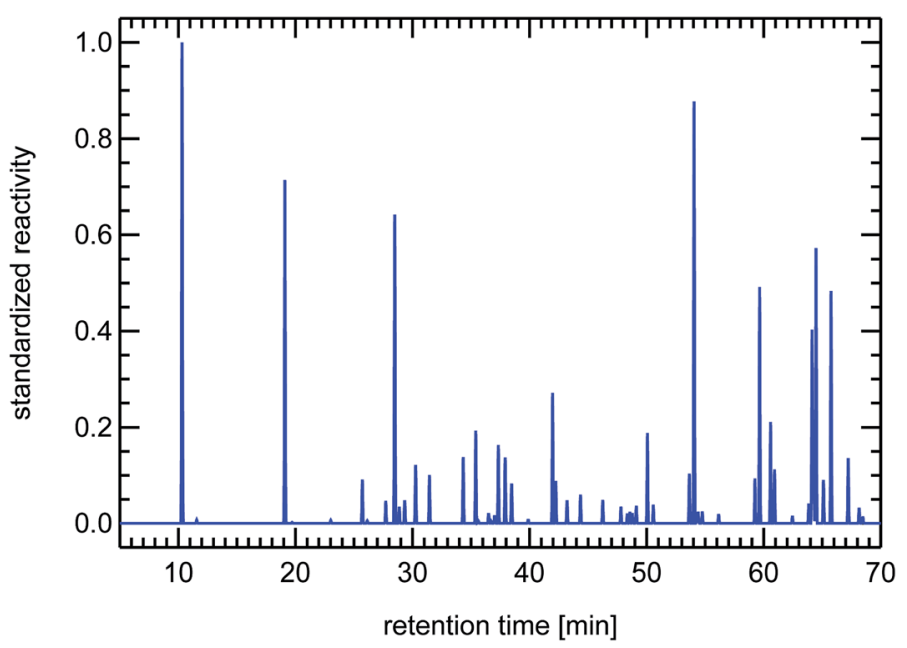

Fig. 16 Synthesized reactivity chromatogram of a petrol passenger car under cold-start conditions.

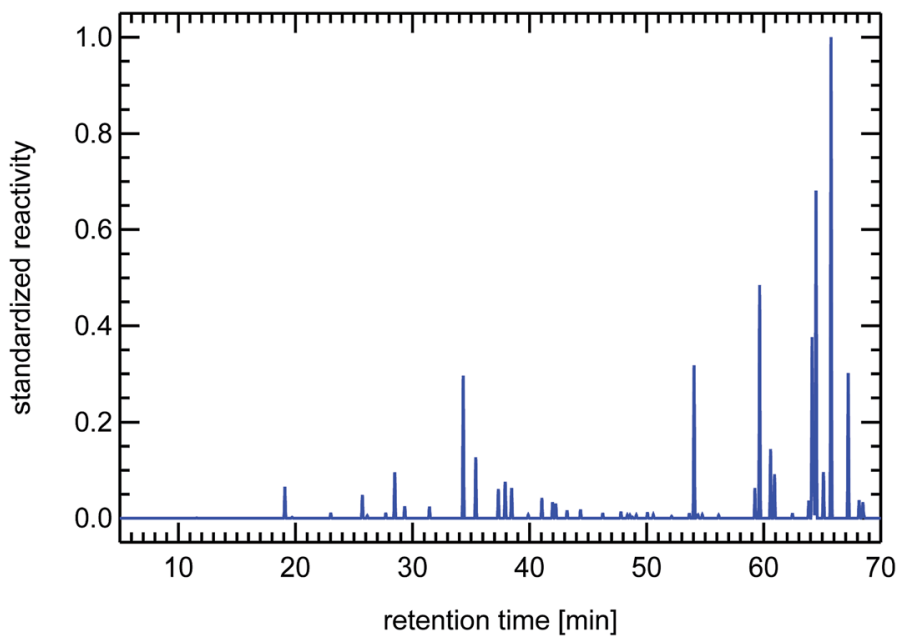

Fig. 17 Synthesized reactivity chromatogram of a petrol passenger car for warm conditions. 


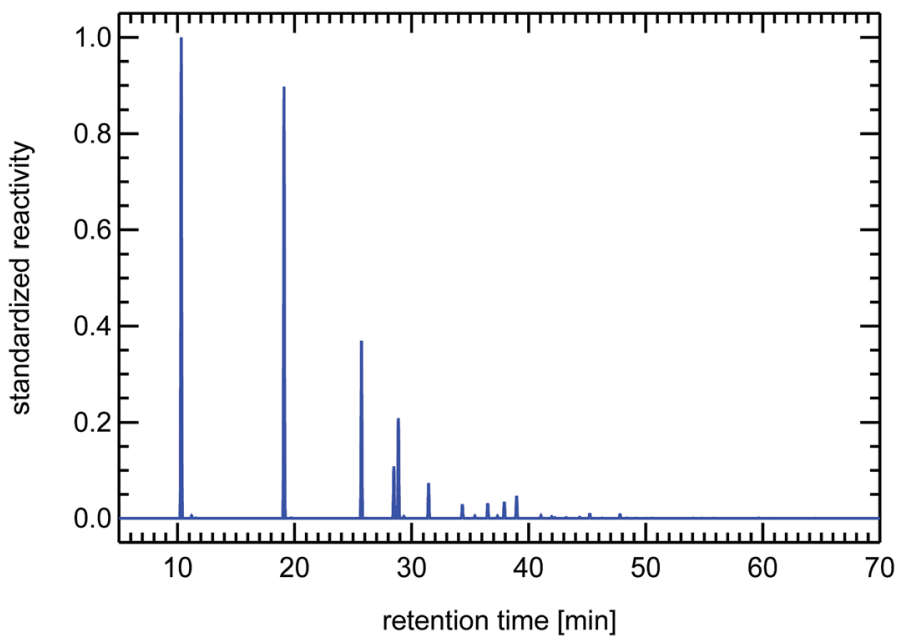

Fig. 18 Synthesized reactivity chromatogram of a diesel passenger car under cold-start conditions.

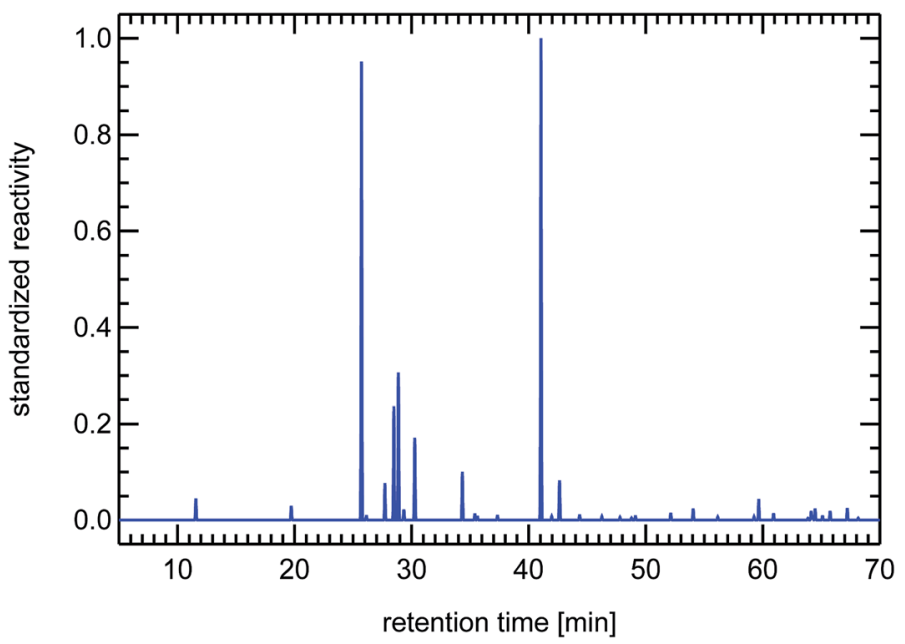

Fig. 19 Synthesized reactivity chromatogram of a diesel passenger car for warm conditions.

the large concentration and reactivity of isoprene. Isoprene is the most prominent $\mathrm{VOC}_{i}$ species from biogenic sources and is related to the emissions of broadleafed trees like oaks and beeches. Other trees like conifers emit specific VOCs called mono-terpenes which are not shown here, but whose fingerprints are also clearly distinguishable from car emissions. The next large reactivity peak at a retention time of $65 \mathrm{~min}$ in Fig. 20 is such a monoterpene called sabinene which, as an exception, is also emitted by broad-leafed trees. Other fingerprints, for example from petrol cars or from solvents, are almost not visible, because airmasses originating in cities and traveling to remote locations are either 


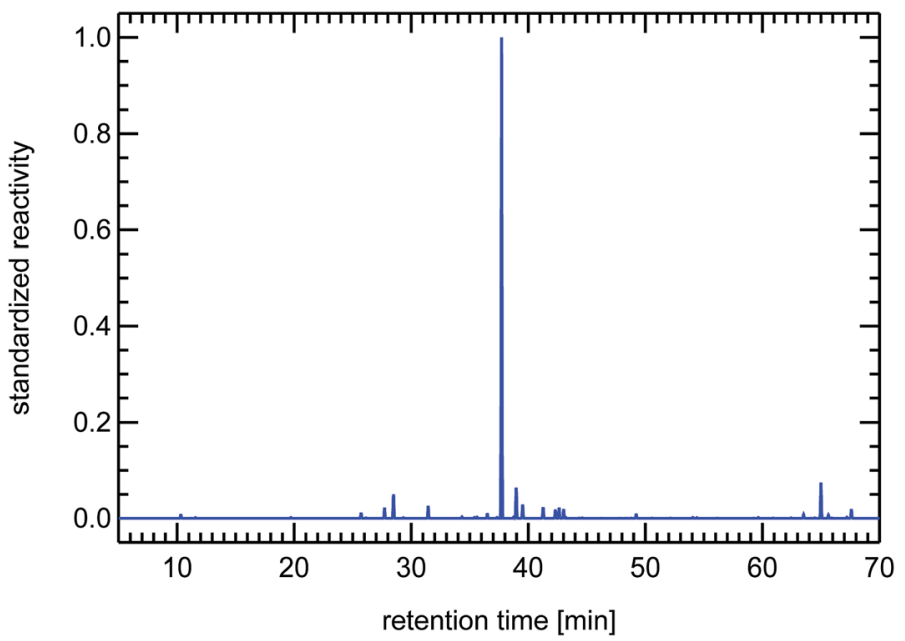

Fig. 20 Synthesized reactivity chromatogram of an air sample taken in summer 2003 in the forest near the Research Centre Jülich.

considerably diluted or their VOC content is degraded by reaction with $\mathrm{OH}$ radicals, a line-of-thought we will resume in Section 4.3.

3.1.2 VOC fingerprints found in air samples taken in inner city districts. With the information from the previous sections we can now try to match the source VOC fingerprints to those from ambient air samples, for example from inner city districts or roads. Just as an example, Fig. 21 shows the VOC fingerprint of an ambient air sample taken in 1997 in the inner city district of Munich. This fingerprint from Munich in 1997 can directly be compared to a fingerprint taken in 2014 in a street tunnel in Berlin (see Fig. 22) and to the exhaust of a petrol car

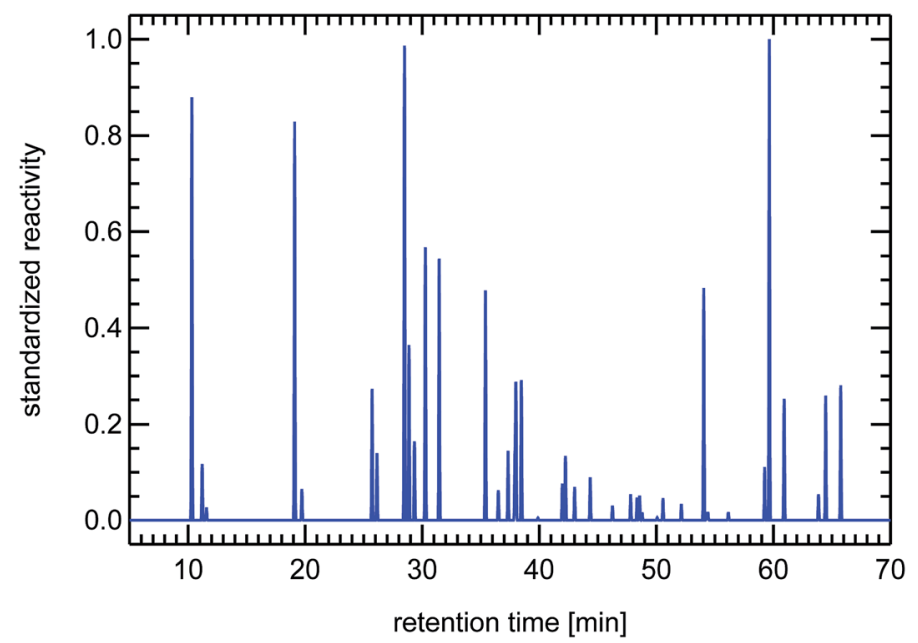

Fig. 21 Synthesized reactivity chromatogram of an air sample taken in 1997 in Munich, "Garmischer Straße". 


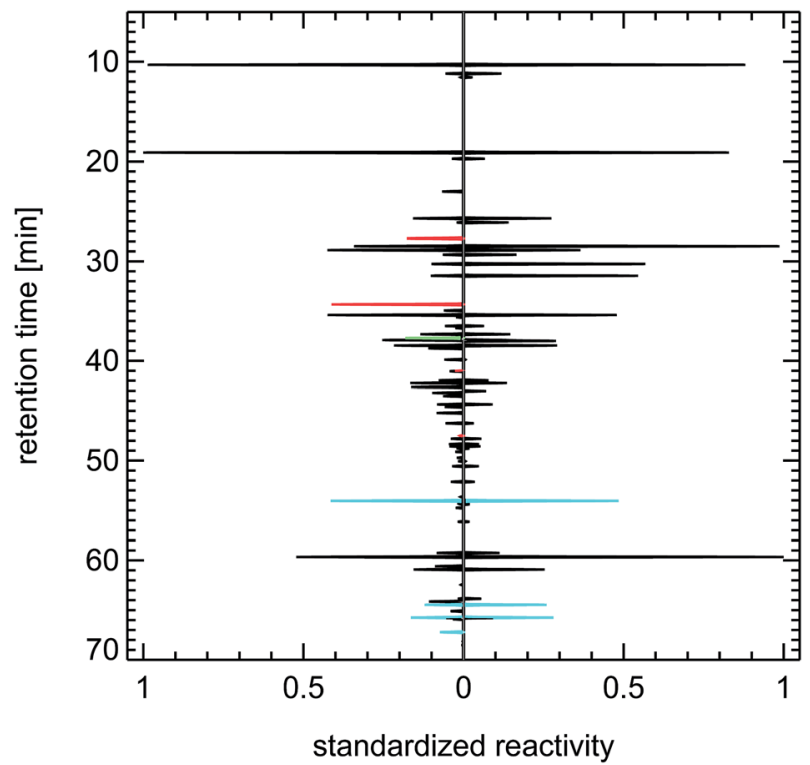

Fig. 22 Contrasting juxtaposition of synthesized reactivity chromatograms from air samples taken in 2014 in Berlin, "Tiergartentunnel" (left panel), and taken in 1997 in Munich, "Garmischer Straße" (right panel); red: methanol, ethanol, propanol; green: isoprene; blue: toluene, trimethylbenzenes.

under cold-start conditions (see Fig. 23). These juxtapositions show a striking concurrence between traffic dominated air masses in 1997 and 2014 and between air masses from a cold-start petrol car in 2015 and traffic emissions in 1997. The same similarity is found in the comparison of a single chromatogram of the exhaust of a petrol passenger car with the result of a literature study ${ }^{38}$ (see Fig. 24). This proves the persistence of the fingerprint of petrol cars over the years regardless of car design, petrol fuel composition, or author. It also shows that the VOC fingerprint found in inner city districts is indeed related to the fingerprint of petrol cars under cold-start conditions, an observation which was already addressed in Section 1.2.

A close examination of the juxtapositions in Fig. 22-24 reveals one difference between the fingerprints of the 1990s and of today. That is the occurrence of methanol and ethanol in recent air samples of inner city districts and in petrol car exhaust. That feature is most likely caused by the addition of $5 \%$ or $10 \%$ alcohol to petrol fuel in Germany (fuel types called E5 and E10). But the overall effect of that change on the composition of the VOC reactivity in air masses dominated by traffic emissions seems to be negligible.

A recent publication ${ }^{39}$ brought forward the argument that large hydrocarbons from diesel exhaust are underestimated by orders of magnitude because VOCs larger than C12 are not easily observed by current GC systems and therefore have been neglected. Including the reactivity contributed by these large VOCs, the authors of this publication ${ }^{39}$ predict that diesel-related hydrocarbons contribute up to $50 \%$ of the ozone production potential in London during winter-time. We specifically designed a GC system to be able to observe VOCs in the region C8-C16 


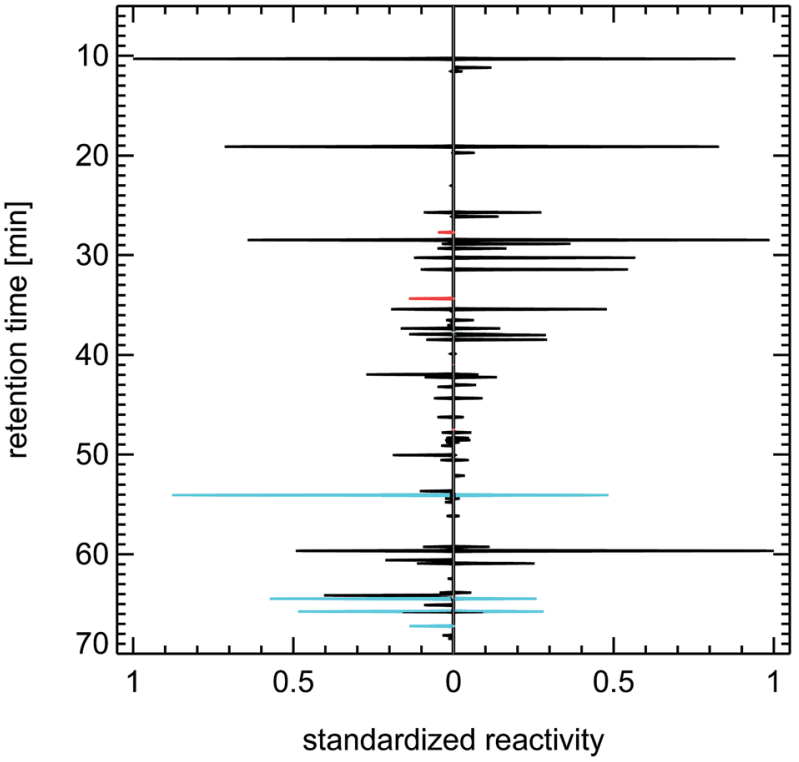

Fig. 23 Contrasting juxtaposition of synthesized reactivity chromatograms from air samples taken from the exhaust of a petrol car under cold-start conditions (left panel), and taken in 1997 in Munich, "Garmische Straße" (right panel); red: methanol, ethanol, propanol; green: isoprene; blue: toluene, trimethylbenzenes.

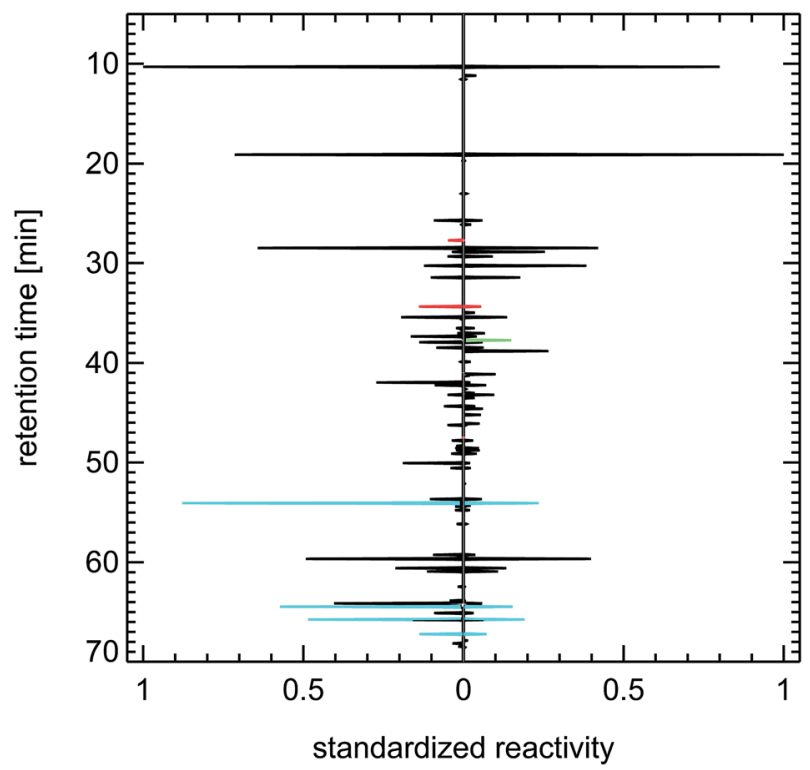

Fig. 24 Contrasting juxtaposition of synthesized reactivity chromatograms from a single air sample taken from the exhaust of a petrol passenger car under cold-start conditions (left panel), and from a literature study (evaluating 200 citations) for a typical petrol passenger car with $\mathrm{GKat}^{38}$ (right panel); red: methanol, ethanol, propanol; green: isoprene; blue: toluene, trimethylbenzenes. 
and found no evidence for such a statement ourselves. We took samples in a street tunnel in Bonn (Germany) and found only $0.3 \%$ of the total VOC mass above C11, the largest VOC included in our standard gas chromatographic analysis. Even if those hydrocarbons would have a larger $\mathrm{OH}$ rate constant than the typical VOC of car exhaust (about $1 \times 10^{-11} \mathrm{~cm}^{3} \mathrm{~s}^{-1}$ ), their total contribution to the VOC reactivity in ambient samples dominated by traffic emissions is expected to be below $3 \%$.

\subsection{The ratio of $\mathrm{VOC} / \mathrm{NO}_{x}$ in inner city districts of Germany}

Here we show the result of ambient observations of the ratio of the reactivities of VOC/ $\mathrm{NO}_{2}$ from inner city districts of Wuppertal, Munich, Augsburg, Düsseldorf, Bad Homburg, and Essen over the years 1994 to 2015 (see Fig. 25). As mentioned before, the reactivities of VOC were determined by adding up the individual reactivities of all $\mathrm{VOC}_{i}$ compounds analyzed from air samples gathered by filling up appropriate Silcosteel canisters within the traffic of major roads of these cities. The reactivities of $\mathrm{NO}_{2}, R_{\mathrm{NO}_{2}}$, were derived for the same time periods from in situ observations of nitrogen oxide mixing ratios measured co-located to the canisters. To account for different ratios of $\mathrm{NO}$ and $\mathrm{NO}_{2}$ in different traffic-, light-, and ozone-conditions, $R_{\mathrm{NO}_{2}}$ was calculated for an average $\mathrm{NO}_{2}$ contribution of $75 \%$ of the sum of observed $\mathrm{NO}$ and $\mathrm{NO}_{2}$. In that respect, the observed reactivity of $\mathrm{NO}_{2}$ was calculated according to the function $R_{\mathrm{NO}_{2}}=k_{\mathrm{OH}+\mathrm{NO}_{2}} \times\left(\mathrm{NO}+\mathrm{NO}_{2}\right) \times 0.75$. Following this approach, the ratio of $R_{\mathrm{VOC}} / R_{\mathrm{NO}_{2}}$ in inner city districts of Germany was around 1.43 in the year 1994 and 0.19 in 2014 .

This result can be compared to another long-term study ${ }^{\mathbf{4 0}}$ of traffic emissions from a spacious road tunnel, the Gubrist tunnel in Switzerland, but that comparison cannot be done straight forward. Since the traffic inside the Gubrist tunnel flows at an average speed of around $90 \mathrm{~km} \mathrm{~h}^{-1}$, the ratio of $R_{\mathrm{VOC}} / R_{\mathrm{NO}_{2}}$ is different compared to a city where the traffic flow is sometimes congested, the average speed is below $50 \mathrm{~km} \mathrm{~h}^{-1}$, and the amount of cold-start petrol cars is larger. The fleet of passenger cars, diesel and petrol, and the contribution of heavy duty cars might not be the same as in Germany. A further difficulty is the type of data reported in the Gubrist tunnel study. That study reports emission factors for total VOC (TVOC) and $\mathrm{NO}_{x}$ and not reactivities. Due to all of these differences it is very difficult to derive and to compare absolute values of the $R_{\mathrm{VOC}}$ and $R_{\mathrm{NO}_{2}}$

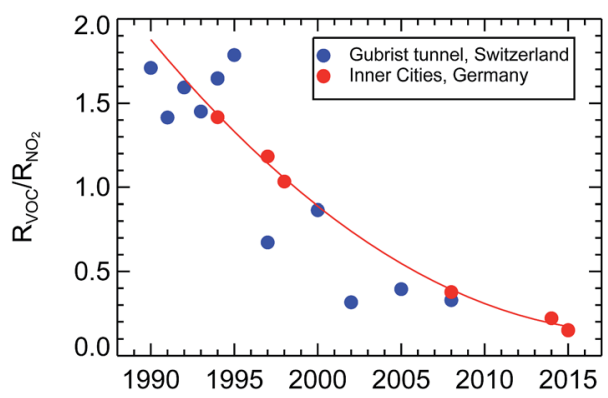

Fig. 25 Observed reactivity ratios of $\mathrm{VOC}$ and $\mathrm{NO}_{2}, R_{\mathrm{VOC}} / R_{\mathrm{NO}_{2}}$, over the years $1990-2015$ from inner city districts in Germany (this paper) and (scaled, see text) inside the Gubrist road tunnel${ }^{40}$ in Switzerland. 
reactivities from the Gubrist tunnel. For our purpose it is enough to see the trend from this profound investigation offers an independent confirmation of our statement of a large decrease of the $R_{\mathrm{VOC}} / R_{\mathrm{NO}_{2}}$ ratio in traffic emissions over the last two decades in Germany. To compare the trend of the Gubrist tunnel results to the trend in our own data set, one has to assume that the VOC composition of traffic emissions did not change over time, something we called a "persistent VOC fingerprint" before. With this assumption, one can simply scale the scattered mass ratios TVOC/NO $\mathrm{NO}_{x}$ from the Gubrist tunnel study of the time period 19901995 to match the best-fit line (the thin red line in Fig. 25) and compare the two trends. Basically, the trends for the Gubrist road tunnel in Switzerland and for inner city districts in Germany show the same behaviour, a decrease of a factor of 7.5 of the reactivity ratio $R_{\mathrm{VOC}} / R_{\mathrm{NO}_{2}}$ within 20 years (derived for the thin red line in Fig. 25). That trend is much larger than what we expected from the VOC and $\mathrm{NO}_{x}$ emission inventories for Germany in Section 1.3.2, that is a factor of 2.9 in 20 years. For this comparison we again use the assumption that mass ratio and reactivity ratio for $\mathrm{VOC} / \mathrm{NO}_{x}$ for traffic emissions have a simple and constant scaling factor. Since we have shown in Section 1.3.1, that the observed concentration trend in traffic dominated inner city districts of Germany follows the estimated trend for $\mathrm{NO}_{x}$ traffic emissions, this discrepancy has to come from the trend of traffic VOC emissions. There is no published observed average trend of VOC concentrations for inner city districts in Germany to compare to. Our observations of the $R_{\mathrm{VOC}} / R_{\mathrm{NO}_{2}}$ ratios suggest a larger decrease of VOC traffic emissions than the published emission inventories. One reason might be the difficulty arising in the determination of the VOC emission trend from the "coldstart" burst of VOCs in the first minutes after starting a petrol car. This short transitory period during the drive emits on the order of $90 \%$ of all VOC emissions of a petrol car (see Section 1.2). It is very difficult to incorporate this kind of process into an inventory calculation. For $\mathrm{NO}_{x}$, such a difficulty does not appear. Furthermore, it has to be expected that the car manufacturers have shortened that time period by optimizing the catalytic converter efficiency of the G-Kats over the years. Anyhow, such a large decrease of VOC relative to $\mathrm{NO}_{x}$ offsets the photochemical ozone production rate, as will be studied in Section 4.3.

For other countries, the VOC/ $\mathrm{NO}_{2}$ ratio and its trend might be different. It depends on the specific vehicle fleets for each country, e.g. if they are dominated more by petrol-engined vehicles rather than diesel or vice versa. For example, American vehicles have mostly used petrol engines for decades (3\% (ref. 41) diesel contribution in 2012), whereas in France 78\% (ref. 41) of vehicles use diesel fuel. And Switzerland and Germany are in-between with 22\% (ref. 41) and 26\% (ref. 13) of the passenger fleet using diesel fuel in 2010, respectively.

\section{Discussion}

The following section conceptually depicts the chemical changes an air parcel experiences when it is released inside a city, is loaded with traffic emissions inside a street tunnel or a main road, travels forward driven by the wind, passes minor streets and the city limit, going further into more rural environments, finally reaching a large forest or agriculturally dominated region. Here, we are not interested in details, just focusing on the concept. In reality, emissions might be different for different roads or cities, the wind might blow faster or slower, the 
light might change due to clouds and so on, there are a magnitude of possibilities which influence a specific location or point in time. We have to bear in mind that our concept wants to show only the generic features and does not have to be applicable for all possible conditions.

\subsection{The photochemical production of ozone}

In this paper, we want to explore, how the change of the VOC and the $\mathrm{NO}_{x}$ emissions from traffic over the last 20 years will affect the production of ozone, a secondary pollutant and a risk for human health. We have seen that for this time period the observed hazardous ozone concentrations decreased considerably in Germany and almost reached a state where they are no longer a risk for human health (Section 1). To substantiate the background for this observation, we have to understand how ozone is produced by photochemical processes, especially in smog episodes. Ozone is produced in the degradation of VOCs by $\mathrm{OH}$ radicals in the presence of nitrogen oxides. In this degradation process, peroxy radicals ROx are generated which react with nitrogen monoxide NO to form nitrogen dioxide $\mathrm{NO}_{2}$. $\mathrm{NO}_{2}$ is subsequently photolysed to give back $\mathrm{NO}$ and generate ozone. Besides this pathway, $\mathrm{NO}_{2}$ can react with $\mathrm{OH}$ to form nitric acid. This latter process reduces the potential degradation of VOCs since the concentration of $\mathrm{OH}$ radicals is lessened. Nitrogen oxides have therefore a dual impact on ozone production. In the form of $\mathrm{NO}$, they amplify the production rate, in the form of $\mathrm{NO}_{2}$ they withdraw the major agent from the ozone production process, the $\mathrm{OH}$ radical. The production rate of ozone depends in a nonlinear way on the concentrations of nitrogen oxides, VOCs, ozone itself, light intensity, humidity, temperature, and other parameters. To understand these complex relationships we used the master chemical mechanism MCM 3.1. ${ }^{37}$

\subsection{The box model approach}

The master chemical mechanism MCM 3.1, ${ }^{37}$ slightly extended with new information, ${ }^{7}$ consists of 14025 reactions and 4575 species. It is used here to calculate the concentration of $\mathrm{OH}$ radicals in the presence of certain amounts of VOC and $\mathrm{NO}_{x}$ for typical summertime conditions in Germany. The major ingredients of this set up were a temperature of $25{ }^{\circ} \mathrm{C}$, a relative humidity of $75 \%$, an ozone concentration of $60 \mathrm{ppb}$, and photolysis frequencies $J_{\mathrm{O}^{1} \mathrm{D}}$ and $J_{\mathrm{NO}_{2}}$ of $2.9 \times 10^{-5} \mathrm{~s}^{-1}$ and $8.4 \times 10^{-3} \mathrm{~s}^{-1}$, respectively. The ratio of $\mathrm{NO}_{2} / \mathrm{NO}_{x}$ is on the order of 0.75 under these conditions. We started with $\mathrm{NO}_{2}$ and VOC concentrations equivalent to $R_{\mathrm{NO}_{2}}$ and $R_{\mathrm{VOC}}$ reactivities each of $100 \mathrm{~s}^{-1}$. The relative mix of the different VOCs was borrowed from the results of ambient observations in Munich 1997. The VOC fingerprint of these air masses, very similar to cold-start petrol car conditions, was already shown in Fig. 21. The fate of this $\mathrm{NO}_{2}$ \& VOC mixture was then calculated by the model for a time interval of 10 minutes to allow $\mathrm{NO}$ and $\mathrm{NO}_{2}$ and the $\mathrm{OH}$ radicals to reach a quasi steady-state. After that time, the local ozone production rate $P_{\mathrm{O}_{3}}$ was calculated according to $P_{\mathrm{O}_{3}}=\Sigma\left(k_{\mathrm{ROx}_{i}+\mathrm{NO}} \times\left[\mathrm{ROx}_{i}\right] \times[\mathrm{NO}]\right)$, where the $\mathrm{ROx}_{i}$ denote the different peroxy radicals including $\mathrm{HO}_{2}$. This ozone production rate and the related $\mathrm{NO}_{2}$ and VOC reactivities were stored. The whole process started again with a slightly different $\mathrm{NO}_{2}$ \& VOC mixture until the desired surface area of $\mathrm{NO}_{2}$ and VOC each spanning 0.1 to $100 \mathrm{~s}^{-1}$ was filled with enough supporting points to allow 
for a thorough representation of the internal structure within the ozone production process (see next the section).

\subsection{The result of box model calculations}

Fig. 26 shows the result of our approach to understand the relation between the reactivities $R_{\mathrm{VOC}}$ and $R_{\mathrm{NO}_{2}}$ with respect to photochemical ozone production. The important point here is that the use of the parameter "OH-reactivity" instead of concentrations simplifies the understanding of ozone production, since this integrative single parameter almost entirely determines the magnitude of the ozone production rate, ${ }^{7}$ and not the complex peculiarities of the different degradation processes of the set of VOCs. This feature enables us to follow an air parcel within the same framework even if the VOC mixture is changing with time, for example by the addition of biogenic emissions. In Fig. 26, we start at reactivities for $R_{\mathrm{NO}_{2}}$ and $R_{\mathrm{VOC}}$ of $70 \mathrm{~s}^{-1}$ and $100 \mathrm{~s}^{-1}$, respectively, to represent typical ambient concentrations in a street tunnel or main road in a German city and the observed reactivity ratio $R_{\mathrm{VOC}} / R_{\mathrm{NO}_{2}}$ of 1.4 for the year 1994 . On its way to leave the city, that air parcel picks up some more emissions when passing minor streets, but those are small contributions compared to the starting concentrations. The

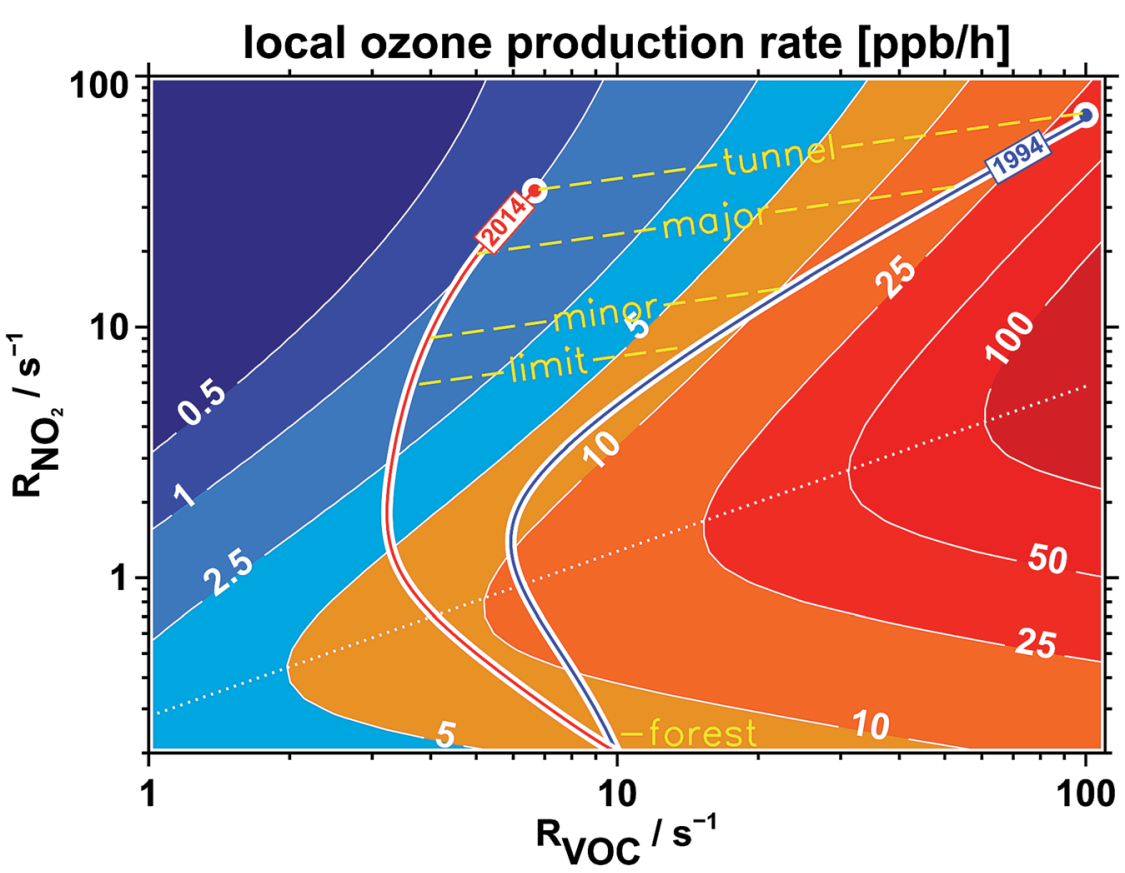

Fig. 26 Local ozone production rate $\left(\mathrm{ppb} \mathrm{h}^{-1}\right)$ for typical summer time conditions in Germany (result of MCM-3.1-model calculations') as a function of VOC and $\mathrm{NO}_{2}$ expressed by their reactivity versus $\mathrm{OH}$ radicals $\left(R_{\mathrm{VOC}}\right.$ and $\left.R_{\mathrm{NO}_{2}}\right)$. The two trajectories denote typical air masses for 1994 (blue) and 2014 (red) traveling from inner city locations (street tunnel, major and minor streets, city limit) into regions dominated by biogenic emissions (forest). The dotted line separates the VOC (above the line) and $\mathrm{NO}_{x}$ (below the line) limited regimes of ozone production. 
dominant process while travelling here is dilution, that means mixing-in air containing very much lower concentrations from the background. This will influence both the VOC and the $\mathrm{NO}_{2}$ concentrations in an equal manner. So for the first part of the air trajectory shown for the year 1994 in Fig. 26, it is following a dilution path. As the reactivities approach background conditions (we have chosen $R_{\mathrm{VOC}}=3 \mathrm{~s}^{-1}$ and $R_{\mathrm{NO}_{2}}=0.2 \mathrm{~s}^{-1}$ ), the trajectory seems to turn around. The reason is that when the trajectory moves towards the forest in our example, we mix-in more and more biogenic VOC emissions. The end-point of the trajectory reaches background conditions for $R_{\mathrm{NO}_{2}}$ but approaches $10 \mathrm{~s}^{-1}$ for $R_{\mathrm{VOC}}$, a value we would expect for a forest in Germany. Then we repeat that course of action to represent the year 2014, this time starting at $35 \mathrm{~s}^{-1}$ for $R_{\mathrm{NO}_{2}}$ and $6.5 \mathrm{~s}^{-1}$ for $R_{\mathrm{VOC}}$ to follow the observed trends from Section 3.2 (a factor of 2 for $R_{\mathrm{NO}_{2}}$ and a factor of 15 for $\left.R_{\mathrm{VOC}}\right)$. The end-point of the 2014-trajectory is the same as that of the 1994trajectory, since we assume that the background concentrations at the final point inside the forest did not change over time. But the trajectory itself to reach that end-point is very different. Due to the large decrease of the starting $R_{\mathrm{VOC}}$ reactivity, the trajectory seems to avoid the regions of large ozone production. The reason is that due to the small $R_{\mathrm{VOC}} / R_{\mathrm{NO}_{2}}$ reactivity ratio, $\mathrm{OH}$ radicals primarily react with $\mathrm{NO}_{2}$ (thereby producing $\mathrm{HNO}_{3}$ ) instead of reacting with VOC (producing ozone in the latter case).

For sure, Fig. 26 only illustrates the concept of an air parcel starting in a city and moving to rural areas with conditions suitable to represent Germany. But the figure discloses the internal structure of photochemical ozone production. And that is the important point. No matter how a real-world trajectory would travel, as long as it starts at a location within the VOC limited regime (above the dotted line in Fig. 26) and has to reach a biogenic environment, the situation will be as discussed in the text above. If the wind has a fast speed or the forest is close to the city, the trajectory will be more straight than the one shown in Fig. 26. But the ozone production rate encountered and therefore the additional ozone the air parcel accumulates during its travel will be very much less nowadays than in the 1990s due to the large decrease of VOC traffic emissions, which is in the end an achievement of a political process. This VOC decrease would be especially beneficial if the air parcels would move around for a long time within the same area, like, for example, if they were trapped within a stagnant summertime high pressure system. In that case, the high pressure system can work like a reactor, accumulating and processing traffic emissions for an enlarged period of time. The normal background dilution process would be omitted because the air parcels would not be able to escape the "reactor" for some time. In other words, the "fuel" needed to feed a significant photochemical ozone production in the vicinity of cities, the VOCs released by traffic emissions, is nowadays almost gone.

There is one basic point concerning the validity of this simple box model approach which is not addressed until now. For the representation within a simple framework we have assumed a typical summertime $\mathrm{NO}_{2} / \mathrm{NO}_{x}$ ratio of $75 \%$ everywhere. It is known that petrol car exhaust mainly ${ }^{12}$ consists of NO $\left(\mathrm{NO}_{2} / \mathrm{NO}_{x} \approx 0.05\right)$. The same is true for diesel cars from the $1990 \mathrm{~s}$. Nowadays, the ratio of $\mathrm{NO}_{2} / \mathrm{NO}_{x}$ for diesel cars (above EURO-3) has been shifted ${ }^{12}$ towards $\mathrm{NO}_{2}$ $\left(\mathrm{NO}_{2} / \mathrm{NO}_{x} \approx 0.40\right)$, for example to facilitate the oxidation of soot deposited by a diesel particulate filter (DPF). With the consequence that in the 1990s, NO from car exhaust in city districts did rapidly react with ambient ozone, diminishing 
ozone almost to zero. Since the NO emissions were very large in street tunnels or main roads, ozone was gone there and NO was left over. As a consequence, the $\mathrm{NO}_{2} / \mathrm{NO}_{x}$ ratio in regions dominated by traffic emissions was low in the year 1994 $(\approx 30 \%)$ and larger in the year $2014(\approx 50 \%$, see Fig. 11). The trajectory for the year 1994 in Fig. 26 would have started at a lower $\mathrm{NO}_{2}$ reactivity and at a larger NO concentration as anticipated. This would have driven an even larger ozone production rate than illustrated in the figure. After a relatively short period, this virtual trajectory considering a large NO contribution would converge against the depicted trajectory and would follow it for the rest of the time. For the year 2014, the deviation between the virtual (representing more NO) and the depicted trajectory would have been very much less because the $\mathrm{NO}_{2} / \mathrm{NO}_{x}$ ratio from diesel car exhaust would be near to the typical condition of $75 \%$ from the start. Overall, we would expect a small change if we use a more complex framework able to handle different $\mathrm{NO}_{2} / \mathrm{NO}_{x}$ ratios for the calculation of ozone production rates. The result would even strengthen our conclusion of a strong reduction of photochemical ozone production over the last 20 years in Germany.

\section{Conclusions}

Traffic emissions of VOC have been significantly decreased in Germany over the last 20 years. Ambient observations suggest a reduction on the order of a factor of 15 in 20 years, which would mean $14.5 \%$ per year. That is a remarkable achievement. This decrease is most probably responsible for the overall improvement of the compliance with EU ozone regulations for human health in Germany.

Traffic emissions of $\mathrm{NO}_{x}$ did not show the same decline as the VOC emissions. In fact, they stayed almost the same over time. If the decrease of $\mathrm{NO}_{x}$ traffic emissions was parallel to the VOC decrease, the trajectory for the year 2014 in Fig. 26 would have been on top of the trajectory for 1994, just starting at a later stage down the 1994 trajectory. This would suggest a less favorable decrease of ozone production along the trajectory for that case. On the other hand, a faster reduction of $\mathrm{NO}_{x}$ traffic emissions would have avoided the frequently observed exceedance of the $\mathrm{NO}_{2}$ limit for the improvement of human heath, ${ }^{4}$ which is basically a problem of traffic emissions in inner city districts. If the decrease in $\mathrm{NO}_{x}$ traffic emissions would start now, both benefits can be achieved: the avoidance of large ozone production and that of large $\mathrm{NO}_{2}$ concentrations. Fig. 13 suggests how this can be achieved. The emissions of heavy-duty-vehicles and buses (called HGV and LCV in that figure) are estimated to dominate $\mathrm{NO}_{x}$ traffic emissions in German cities nowadays. Their $\mathrm{NO}_{x}$ emissions are still large, although most of them are equipped with catalytic converters. The reason seems to be, that due to the relatively slow speed in city districts, the engine exhaust does not heat-up the converters enough to be efficient. If this heating-up could be managed by an additional power source at all vehicle speeds, $\mathrm{NO}_{x}$ traffic emissions in inner city districts would be considerably reduced. Of course one would have to ensure that the $\mathrm{NO}_{x}$ reduction techniques for heavy-duty-vehicles and buses do not introduce other pollutants with a similar potential for health-risks as $\mathrm{NO}_{2}$. This has to be investigated yet. Maybe, in the end, other concepts like electric buses and fuel-cell-vehicles are a better choice. 


\section{Appendix}

The emission categories for Fig. 10a and b contain the following subcategories:

\subsection{Emission category "road traffic"}

Passenger cars, light duty vehicles, heavy duty vehicles and buses, mopeds \& motorcycles, gasoline evaporation, automobile tyre and brake wear, automobile road abrasion.

\subsection{Emission category "residential"}

Stationary, household and gardening (mobile), public electricity and heat production.

\subsection{Emission category "industry"}

Petroleum refining, manufacture of solid fuels and other energy industries, stationary combustion in manufacturing industries and construction - iron and steel \& non-ferrous metals \& chemicals, pulp, paper and print \& food processing, beverages and tobacco \& non-metallic minerals, mobile combustion in manufacturing industries and construction, stationary combustion in manufacturing industries and construction, international aviation LTO (civil), domestic aviation LTO (civil), cement production, lime production, glass production, quarrying and mining of minerals other than coal, construction and demolition, storage, handling and transport of mineral products, other mineral products, ammonia production, nitric acid production, adipic acid production, carbide production, titanium dioxide production, soda ash production, chemical industry, storage, handling and transport of chemical products, iron and steel production, ferroalloys production, aluminium production, magnesium production, lead production, zinc production, copper production, nickel production, other metal production, storage, handling and transport of metal products, pulp and paper industry, food and beverages industry, other industrial processes, wood processing, production of POPs, consumption of POPs and heavy metals, other production, consumption, storage, transportation or handling of bulk products, commercial/institutional: stationary, commercial/institutional: mobile.

\subsection{Emission category "agriculture"}

Manure management - dairy cattle \& non-dairy cattle \& sheep \& swine \& buffalo \& goats \& horses \& mules and asses \& laying hens \& broilers \& turkeys \& other poultry \& other animals, inorganic N-fertilizers (includes also urea application), animal manure applied to soils, sewage sludge applied to soils, other organic fertilizers applied to soils, urine and dung deposited by grazing animals, crop residues applied to soils, indirect emissions from managed soils, farm-level agricultural operations including storage, handling and transport of agricultural products, off-farm storage, handling and transport of bulk agricultural products, cultivated crops, use of pesticides, field burning of agricultural residues, agriculture other, agriculture/forestry/fishing: stationary, agriculture/forestry/fishing: off-road vehicles and other machinery, agriculture/forestry/fishing: national fishing. 


\subsection{Emission category "solvents"}

Domestic solvent use including fungicides, road paving with asphalt, asphalt roofing, coating applications, degreasing, dry cleaning, chemical products, printing, other solvent use, other product use.

\subsection{Emission category "miscellaneous"}

This category is calculated from the category called "NATIONAL TOTAL" minus the sum of the categories already used in the figures. It contains categories like "military", "fugitive", "waste" and "solvents" in case of $\mathrm{NO}_{x}$ and "residential" in case of VOC.

\section{Acknowledgements}

This work was supported by the "Federal Ministry of Education and Research" (BMBF) under grant numbers 07TFS45/3 and FKZ19B98118/0, by the "Federal Ministry for Economic Affairs and Energy" (BMWI) under grant number 03ET6036D, and by the town council of Bad Homburg via the project "Analyse der lokalen Luftqualität der Stadt Bad Homburg, 2014". The authors wish to thank Hermann-Josef Buers for his assistance in the set-up of the GC system and the analysis of its results. We also acknowledge the kind forwarding of the preliminary surface ozone data from the Global Atmosphere Watch station "Meteorological Observatory Hohenpeissenberg”, German Meteorological Service, by Stefan Gilge.

\section{References}

1 P. J. Crutzen, Annu. Rev. Earth Planet. Sci., 1979, 7, 443-472.

2 R. G. Derwent, A. J. Manning, P. G. Simmonds, T. G. Spain and S. O'Doherty, Atmos. Environ., 2013, 80, 361-368.

3 O. R. Cooper, D. D. Parrish, J. Ziemke, N. V. Balashov, M. Cupeiro, I. E. Galbally, S. Gilge, L. Horowitz, N. R. Jensen, J.-F. Lamarque, V. Naik, S. J. Oltmans, J. Schwab, D. T. Shindell, A. M. Thompson, V. Thouret, Y. Wang and R. M. Zbinden, Elementa, 2014, 2, 000029.

4 U. Dauert, S. Feigenspan, A. Minkos and M. Langner, Luftqualität 2014, Vorläufige Auswertung, Umweltbundesamt, Deutschland, Dessau-Roßlau, January 2015, pp. 11-12.

5 Information über Abgase des Kraftfahrzeugverkehrs, ed. P. Rabl, Bayrisches Landesamt für Umweltschutz, Augsburg, Germany, 2003.

6 R. Pischinger, M. Kell and T. Sams, Thermodynamik der Verbrennungskraftmaschine: Der Fahrzeugantrieb, Springer, Wien, Austia, New York, USA, 3rd edn, 2009.

7 D. Klemp, D. Mihelcic and B. Mittermaier, Messung und Bewertung von Verkehrsemissionen, Schriften des Forschungszentrums Jülich, Energy \& Environment, Jülich, Germany, 1st edn, 2012, vol. 21.

8 D. Hassel, P. Jost, F.-J. Weber, F. Dursbeck, K.-S. Sonnborn and D. Plettau, Abgas-Emissionsfaktoren von PKW in der Bundesrepublik Deutschland Abgasemissionen von Fahrzeugen der Baujahre 1986 bis 1990 (Forschungsbericht 
10405152 und 10405509 im Auftrag des Umweltbundesamtes), Erich Schmid Verlag, Berlin, Germany, 1994.

9 EC Commission Regulations No 91/441/EWG, 91/441/EWG, 94/12/EG, 98/69/EG, 98/69/EG, EG 715/2007 with EG 692/2008 and EG 459/2012 implementing and amending Regulations of the European Parliament and of the Council on typeapproval of motor vehicles with respect to emissions from light passenger and commercial vehicles, European Commission, Brussels, Belgium, 1991-2012.

10 Gesetz zur stärkeren Berücksichtigung der Schadstoffemissionen bei der Besteuerung von Personenkraftwagen (Kraftfahrzeugänderungsgesetz 1997KraftStÄndG 1997), Deutscher Bundestag, Bonn, Germany, 18 April 1997.

11 D. C. Carslaw, S. D. Beevers, J. E. Tate, E. J. Westmoreland and M. L. Williams, Atmos. Environ., 2011, 45, 7053-7063.

12 M. Rexeis, S. Hausberger, J. Kühlwein and R. Luz, Update of emission factors for Euro 5 and Euro 6 vehicles for the HBEFA version 3.2. TUG report I-31/2013/Rex EM-I 2011/20/679, TU Graz, Graz University of Technology, Graz, Austria, 2013.

13 Fahrzeugzulassungen: Bestand an Kraftfahrzeugen nach Umwelt-Merkmalen; Statistische Mitteilungen des Kraftfahrt-Bundesamtes FZ 13, KraftfahrtBundesamt, Flensburg, Germany, 2015.

14 M. W. Lesley and L. D. Schmidt, Surf. Sci., 1985, 155, 215-240.

15 Aktualisierung "Daten- und Rechenmodell: Energieverbrauch und Schadstoffemissionen des motorisierten Verkehrs in Deutschland 1960-2030" (TREMOD, Version 5.3) für die Emissionsberichtserstattung 2013, ed. W. Knörr, ifeu Institut für Energie- und Umweltforschung Heidelberg $\mathrm{GmbH}$, Heidelberg, Germany, 2012.

16 S. Hausberger, M. Rexeis, M. Zallinger and R. Luz, Emission Factors from the Model PHEM for the HBEFA Version 3, Report Nr. I-20/2009 Haus-Em 33/08/679 from 07.12.2009, TU Graz, Graz University of Technology, Graz, Austria, 2009.

17 ERMES: European Research Group on Mobile Emission Sources, Information Paper"Diesel light duty vehicle $N O_{x}$ emission factors", ERMES 2015-10-09, INFRAS, Bern, Switzerland, 2015.

18 National Trend Tables for the German Atmospheric Emission Reporting, ANNEX 1: National sector emissions: Main pollutants, particulate matter, heavy metals and persistent organic pollutants, Excel spreadsheets DE_2015_Table_I_1990.xls DE_2015_Table_I_2013.xls, ed. P. Gniffke, Umweltbundesamt, Deutschland, Dessau, 27 April 2015.

19 Umweltbundesamt, Entwicklung der Luftqualität in Deutschland, Umweltbundesamt Deutschland, Fachgebiet II 4.2, "Beurteilung der Luftqualität”, Dessau-Roßlau, October 2009, pp. 5-7.

20 U. Kugler, J. Theloke and W. Jörß, Verkehrsemissionsmodellierung Modellvergleich und alternative Szenarien, Umweltbundesamt, Dessau-Roßlau, Germany, 2013.

21 A. Niedojadlo, K. H. Becker, R. Kurtenbach and P. Wiesen, Atmos. Environ., 2007, 41, 7108-7126.

22 T. Schmitz, D. Klemp and D. Kley, Messungen der Immissionskonzentrationen verschiedener Ozonvorläufersubstanzen in Ballungsgebieten und an Autobahnen - Charakterisierung der Emissionsverhältnisse des Straßenverkehrs unter verschiedenen Verkehrssituationen durch Messungen in Quellnähe, Berichte des Forschungszentrums Jülich, Jül-3457, Jülich, Germany, 1997. 
23 S. Urban, Charakterisierung der Quellverteilung von Feinstaub und Stickoxiden in ländlichem und städtischem Gebiet, Schriften des Forschungszentrums Jülich, Energy \& Environment, Jülich, Germany, 2010, vol. 84 .

24 T. Kern, N. Metz and D. Kley, Untersuchungen von Verkehrsabgasemissionen insbesondere im Hinblick auf die Ozonbildung, Abschlussbericht, Forschungszentrum Jülich, Jülich, Germany, 1997.

25 K. Mannschreck, Experimentelle Bestimmung von städtischen Emissionen anhand von Konzentrationsmessungen im Lee einer Stadt, Berichte des Forschungszentrums Jülich, Jül-3846, Jülich, Germany, 2001.

26 D. Klemp, K. Mannschreck, H. Pätz, M. Habram, P. Matuska and F. Slemr, Atmos. Environ., 2002, 36(1), 61-80.

27 B. Mittermaier and D. Klemp, EGU General Assembly 2004, Nice, France, 25 April 2004-30 April 2004.

28 C. Ehlers, Mobile Messungen - Messung und Bewertung von Verkehrsemissionen, Schriften des Forschungszentrums Jülich, Energy \& Environment, Jülich, Germany, 2014, vol. 229.

29 M. Barker, M. Hengst, J. Schmid, H.-J. Buers, B. Mittermaier, D. Klemp and R. Koppmann, Eur. Respir. J., 2006, 27, 929-936.

30 T. Schmitz, D. Hassel and F.-J. Weber, Atmos. Environ., 2000, 34, 4639-4647.

31 B. Mittermaier and D. Klemp, Gefahrstoffe, Reinhaltung der Luft, 2004, vol. 64, pp. 487-494.

32 J. Drummond, A. Volz and D. Ehhalt, J. Atmos. Chem., 1985, 2, 287-306.

33 A. Volz and J. Drummond, Fresenius' Z. Anal. Chem., 1984, 317, 355-358.

34 D. H. Ehhalt, H.-P. Dorn and D. Poppe, Proc. R. Soc. Edinburgh, Sect. B: Biol. Sci., 1991, 97, 17-34.

35 R. Atkinson, S. M. Aschmann and J. Arey, Atmos. Environ., 1990, 24, 2647-2654.

36 A. K. Mollner, S. Valluvadasan, L. Feng, M. K. Sprague, M. Okumura, D. B. Milligan, W. J. Bloss, S. P. Sander, P. T. Martien, R. A. Harley, A. B. McCoy and W. P. L. Carter, Science, 2010, 330, 646-649.

37 S. M. Saunders, M. E. Jenkin, R. G. Derwent and M. J. Pilling, Atmos. Chem. Phys., 2003, 3, 161-180.

38 T. Wiedmann, J. Kersten and K. Ballschmiter, Art und Menge von stofflichen Emissionen aus dem Verkehrsbereich, Akademie für Technikfolgenabschätzung in Baden-Württemberg, Stuttgart, Germany, 2000.

39 R. E. Dunmore, J. R. Hopkins, R. T. Lidster, J. D. Lee, M. J. Evans, A. R. Rickard, A. C. Lewis and J. F. Hamilton, Atmos. Chem. Phys., 2015, 15, 9983-9996.

40 U. Steinemann and F. Zumsteg, Verkehrs- und Schadstoffmessungen $2008 \mathrm{im}$ Gubristtunnel (Traffic and trace gas pollutant measurements 2008 in the Gubrist tunnel); report US 89-16-13, OSTLUFT durch Amt für Abfall, Wasser, Energie und Luft des Kantons Zürich (AWEL), Zürich, Switzerland, updated 25 May 2010.

41 L. Ammoura, I. Xueref-Remy, V. Gros, A. Baudic, B. Bonsang, J.-E. Petit, O. Perrussel, N. Bonnaire, J. Sciare and F. Chevallier, Atmos. Chem. Phys., 2014, 14, 12871-12882. 